\title{
Antimicrobial and enzymatic activity of anemophilous fungi of a public university in Brazil
}

\author{
LAUREANA V. SOBRAL ${ }^{1}$, KELLY N. MELO ${ }^{1}$, CLECIANA M. SOUZA ${ }^{1}$, SÍLVIO \\ F. SILVA ${ }^{1}$, GILVANIA L.R. SILVA ${ }^{1}$, ANDRESSA L.F. SILVA ${ }^{1}$, KATHARINE A.A. \\ WANDERLEY ${ }^{1}$, IDJANE S. OLIVEIRA ${ }^{1}$ and ROBERTA CRUZ ${ }^{2}$
}

\begin{abstract}
${ }^{1}$ Laboratório de Microbiologia e Imunologia, Centro Acadêmico de Vitória, Universidade Federal de Pernambuco, Rua Alto do Reservatório, s/n, Bela Vista, 55608-680 Vitória de Santo Antão, PE, Brazil ${ }^{2}$ Departamento de Micologia, Centro de Ciências Biológicas, Universidade Federal de Pernambuco, Avenida Professor Moraes Rego, 1235, Cidade Universitária, 50670-901 Recife, PE, Brazil
\end{abstract}

Manuscript received on April 3, 2017; accepted for publication on June 20, 2017

\begin{abstract}
To the fungal microbiota the UFPE and biotechnological potential enzymatic and antimicrobial production. Air conditioned environments were sampled using a passive sedimentation technique, the air I ratio and the presence of aflatoxigenic strains evaluated for ANVISA. Icelles were to determine the enzymatic activity of lipase, amylase and protease metabolic liquids to determine antimicrobial activity. Diversity was observed in all CAV environments, $\mathrm{CFU} / \mathrm{m}^{3}$ ranged from 14 to 290 and $\mathrm{I} / \mathrm{E}$ ratio from 0.1 to 1.5 . The of the fungal genera were: Aspergillus (50\%), Penicillium (21\%), Talaromyces (14\%), Curvularia and Paecilomyces (7\% each). Aspergillus sydowii (Bainier \& Sartory) Thom \& Church presented enzymatic activity and the Talaromyces purpureogenus Samson, Yilmaz, Houbraken, Spierenb., Seifert, Peterson, Varga \& Frisvad presented antibacterial activity against all bacteria that all environments present fungal species biodiversity no toxigenic or pathogenic fungi were found, according to ANVISA legislation for conditioned environments and airborne filamentous fungi present potential for enzymatic and antimicrobial activity.
\end{abstract}

Key words: Air quality, bacteria, enzymes, filamentous fungi, refrigerated environments.

\section{INTRODUCTION}

Fungi air, water, soil, animals and food. They colonize substrates, have an extensive geographic distribution and are able to grow under environmental conditions (Oliveira and BorgesPaluch 2015).

Fungal contamination is considered due to the production. Of the filamentous fungi under

Correspondence to: Laureana de Vasconcelos Sobral

E-mail: laureanavsobral@gmail.com adequate conditions of oxygen, temperature and humidity, secondary metabolites (mycotoxins) both and animals, fungi of the genus Aspergillus and Penicillium. A. flavus Link and A. parasiticus Speare produce aflatoxins (Peluque 2014).

Therefore, monitoring air in artificially airconditioned is according to Resolution RE No. 9 of January 16, 2003, the National Agency of Sanitary Surveillance (ANVISA), which defines reference standards cleaning and maintenance of the health and safety of individuals who attend 
public and collective places with conditioned environments. The recommended maximum acceptable contamination of $\leq 750 \mathrm{CFU} / \mathrm{m}^{3}$ and $\leq 1.5$ for the relation between internal and external air the presence of pathogenic and toxigenic fungi (Brazil 2003).

Biotechnically, microbial enzymes are by industries reduced production time, increased scale and purification, specificity and stabilization, as well as easy genetic manipulation (Nagarajan 2012) and high biochemical diversity (Silva et al. 2015) is related to the minimization production (Reinehr et al. 2014) and waste and electric consumption (Silva et al. 2015).

Dispersion and appearance of commercially available antimicrobial-resistant microbes, thus the search for sources of effective antimicrobial agents (Santos et al. 2014) researches with the purpose of intervening, preventing or intensifying the conventional bacterial resistance (Catão et al. 2014).

The antimicrobial using mycelia and liquid metabolites of anemophilous filamentous fungi this may be the first activity. The present study aimed to evaluate the microbiological quality of air, the presence of aflatoxigenic fungi in the climatic environments of the Federal University of Pernambuco/Vitória Academic Center and enzymatic production and antimicrobial activity.

\section{MATERIALS AND METHODS}

\section{SAMPLING AND COLLECTION OF AIR}

The study was conducted at the Federal University of Pernambuco/Vitória Academic Center (UFPE/ CAV) and 82 artificially air-conditioned 3 board of directors, 9 library, 1 auditorium, 15 classrooms, 34 laboratories, 13 administrative rooms, 1 room of the Internal Accident Prevention Commission (CIPA), 5 student assistance centers, 1 teaching staff and an external area located in the courtyard of the main entrance of the CAV for fungi quantification. Non-air-conditioned environments were excluded from the study.

The samples were collected from the central area of the environments through the passive sedimentation technique (Lacaz et al. 1998) on solid culture medium using Petri dishes containing the culture (MEA) and Aspergillus flavus and parasiticus agar (AFPA) for total and aflatoxigenic fungi cultures, respectively. The plates were placed $1 \mathrm{~m}$ the ground and opened for $15 \mathrm{~min}$ bioaerosols, containing microorganisms present in the atmospheric air. The plates were incubated at room temperature $\left(28 \pm 2^{\circ} \mathrm{C}\right)$ for up to days.

\section{MICROBIOLOGICAL ANALYSIS OF AIR}

The colonies present in the respective culture media were quantified and the relation between internal and external air (I/E) was calculated to determine the internal air quality. ANVISA the recommended maximum acceptable microbiological contamination value of $\leq 750 \mathrm{CFU} / \mathrm{m}^{3}$ and $\leq 1.5$ for the relationship between internal and external air (Brazil 2003).

Sedimentation sampling does not directly determine the number of microorganisms present in a given volume of airit is possible to transform the results of this method (number of CFU/unit area) into CFU/volume unit number (Morais et al. 2010). Air sampling by sedimentation was using the following equation described by Friberg et al. (1999):

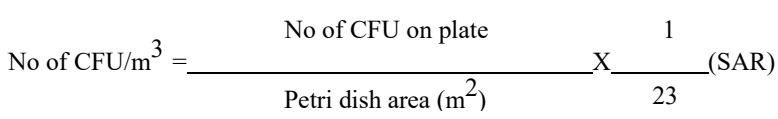

The area of the petri dish $90 \times 15 \mathrm{~mm}$ (our study $0.006 \mathrm{~m}^{2}$ ). SAR is the ratio between the in the air and on the surface of the culture medium. For environments with spontaneous sedimentation and without apparatus that forces the sedimentation of air, this ratio is 1:23 (Morais et al. 2010). 


\section{IDENTIFICATION OF AFLATOXIGENIC FUNGI}

The presence of aflatoxigenic strains revealed by the orange reverse of the AFPA culture medium was evaluated. ANVISA the presence of pathogenic and toxigenic fungi in artificially climatized environments (Brazil 2003).

ISOLATION, IDENTIFICATION AND PRESERVATION OF FUNGI

After in the MEA solid culture medium, the fungal colonies were purified in the same culture medium. After the fungal species, the macroscopic (coloration, appearance and diameter of the colonies) and microscopic (somatic and reproductive microstructures) (Samson and Frisvad 2004) were observed through culture under coveralls (Riddell 1950) and preserved to the Castelani method distilled water and immersion of pure cultures mineral oil. The samples were collected test tubes containing MEA solid culture medium in order to each species identified in the Collection of Cultures Micoteca URM of the Federal University of Pernambuco.

\section{DETERMINATION OF ENZYMATIC ACTIVITY}

To determine the enzymatic activity of the fungi isolated from the air, 14 species were identified according to the number attributed to the isolates [Paecilomyces variotti Bainier (04), Penicillium fellutanum Biourge (06), Aspergillus flavus Link (09), A. parasiticus Speare (14, 20, 27 and 67), A. sydowii (Bainier \& Sartory) Thom \& Church (18), Talaromyces purpureogenus Samson, Yilmaz, Houbraken, Spierenb., Seifert, Peterson, Varga \& Frisvad (21 and 28), Aspergillus japonicas Saito (24), Penicillium oxalicum Currie \& Thom (25), Penicullium chrysogenum Thom (26) and Curvularia lunata (Wakker) Boedijn (49)] for lipase, amylase and protease production, following the methodology Menezes and Hanlin (2004). Mycelial dis were from fungal colonies and peeled into the central area of the Petri dish containing culture media specific for each enzyme incubated for at room temperature. The tests were performed in triplicate for each culture medium.

The lipase reaction was by visualizing the presence of calcium salt crystals of lauric acid and/ or the formation of a clear area around the fungal colony dis. To the production of amylase, $0.1 \mathrm{~N}$ iodine solution was used, allowing the identification of the enzymatic reaction through a translucent halo around the colony. For protease, due to the chemical reaction it was possible to visualize the formation of translucent halo around the colony. After the development of the enzymatic reactions, a halo of enzymatic activity was measured to determine the production potential of the colonies, which is proportional to the halo diameter.

\section{DETERMINATION OF ANTIBACTERIAL ACTIVITY}

Of the species identified, 5 metabolic liquids from the species Paecilomyces variotti Bainier (04), Aspergillus japonicas Saito (24), Talaromyces purpureogenus Samson, Yilmaz, Houbraken, Spierenb., Seifert, Peterson, Varga \& Frisvad (28), Curvularia lunata (Wakker) Boedijn (49), Aspergillus parasiticus Speare (67) were randomly selected to perform antimicrobial activity and determine and purified fungal mycelia dis were cultured in $10 \mathrm{~mL}$ of liquid culture medium Sabouraud brothand incubated at room temperature for 20 days. The liquid metabolite was separated from the mycelium by filtration on sterile filter paper. The metabolic fluid was stored at $4{ }^{\circ} \mathrm{C}$ to perform the antibacterial activity tests and the mycelium was frozen for subsequent extraction of metabolites.

The strains of Gram-negative bacteria: Escherichia coli (ATCC 25922), Shigella flexneri (ATCC 12022), Salmonella typhimurium (ATCC 14028), Serratia marcescens, Klebsiella pneumoniae, Pseudomonas aeruginosa and Gram- 
positive: Staphylococcus aureus (ATCC 29213) and S. aureus ORSA. The bacterial suspensions were prepared in $0.85 \%$ saline and a concentration of 1.5 x $10^{5} \mathrm{CFU} / \mathrm{mL}$ was obtained, from the dilution of the corresponding suspension to the 0.5 tube of the McFarland scale. Five metabolic liquids produced by filamentous fungi from atmospheric air were tested. All experiments were performed in triplicate. The antibacterial activity test was performed the broth dilution method of the ANVISAM7-A6 technical standard. Serial dilutions of metabolic liquids were performed. Positive control of the test was using chloramphenicol antibiotic and negative control of the test, in the absence of antibiotic, to confirm absences of contaminants in the metabolic liquid used in the test was added a column with the pure metabolic liquid. After distribution of the bacterial suspensions, the plates were incubated at $37^{\circ} \mathrm{C}$ for $24 \mathrm{~h} .20 \mu \mathrm{L} \mathrm{2,3,5-triphenyltetrazolium}$ chloride (TTC) $(2 \% \mathrm{v} / \mathrm{v})$ diluted in water was added to all wells after $2 \mathrm{~h}$ of incubation room temperature, bacterial growth. The wells stained in red indicate bacterial growth (Rahman et al. 2004).

The red coloration results from the TTC reaction with hydrogen ions constituted due to cellular respiration, generated by an insoluble reddish solution called formazan, indicating viable bacterial cells in the medium (Rahman et al. 2004).

The reading was performed through visual observation of the lowest concentration of metabolic liquids that inhibit bacterial growth. The test was performed, where was for Petri dishes containing Mueller-Hinton Agar, the plate incubated at $37^{\circ} \mathrm{C}$ for $24 \mathrm{~h}$. Bacterial growth, indicating bactericidal or bacteriostatic action of the fungal metabolic the wells not presentantimicrobial stained red.

The liquid metabolites used in the study were tested in their crude state after filtration. Therefore, the antimicrobial activity the inhibitory concentrations defined for the method in $\mu \mathrm{L} / \mathrm{mL}$ : $500.00 ; 250.00 ; 125.00 ; 62.50 ; 31.25 ; 15.63 ; 7.81$; $3.91 ; 1.95$ and $0.97 \mu \mathrm{L} / \mathrm{mL}$.

\section{RESULTS AND DISCUSSION}

Growth was observed in all environments the lowest amount of $\mathrm{CFU} / \mathrm{m}^{3}$ in the classroom $\left(14 \mathrm{CFU} / \mathrm{m}^{3}\right)$ and with the amount and diversity of the living pharmacy space, the CIPA room and the teaching office (Table I), all the evaluated environments of the CAV were within the ANVISA for microbiological air quality $\left(\leq 750 \mathrm{CFU} / \mathrm{m}^{3}\right)$. Fungal colonies from environments observed in Figures 1 and 2 the colonies before and after purification of the fungal isolates, respectively.

The evaluated environments possibly the access flow of ventilation and passers-by in the environments, atmosphere is influenced by the climate, the interior atmosphere is influenced by building maintenance. Both environments influence human activities, humidity and little temperature, since many indoor fungi grow in a wide temperature range (Araújo and Cabral 2010).

The ratio of fungi quantification of I/E (internal/ external) of the environments surveyed in the CAV (Table I) met the current ANVISA legislation for air quality in conditioned environments $(\leq 1.5)$, this ratio 0.1 to 1.5 , the minimum and maximum, respectively, since the external air quantification was $188 \mathrm{CFU} / \mathrm{m}^{3}$.

The environments that presented an I/E statement in the maximum acceptable limit were: library entrance hall, living pharmacy space, CIPA room and laboratory 1 and teaching room. Fact that the entrance hall of the library by visitors, with human activity showing a direct influence on the live pharmacy laboratory handles plant and soil samples CIPA room is an environment used for meetings the room is relatively frequented by students. In these environments, the values of the air fungi quantification in $\mathrm{CFU} / \mathrm{m}^{3}$ were allowed by ANVISA (750), but the I/E ratio was the limit.

No environment presented aflatoxigenic fungi (Figure 3) in compliance with the aforementioned 

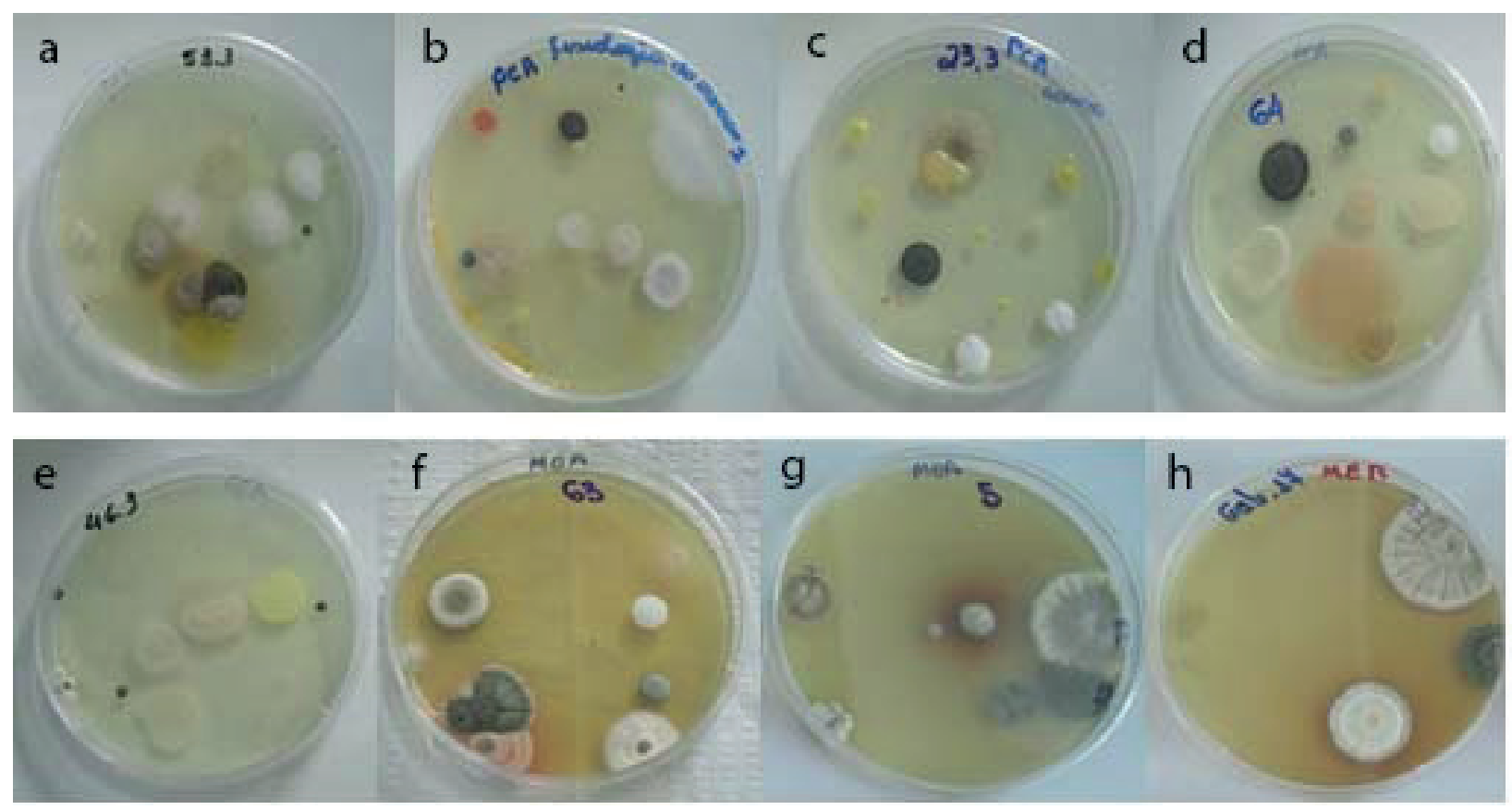

Figure 1 - Diversity of colonies of air bioaerosols of different environments of the Academic Center of Vitória - UFPE/CAV. Internal Commission for Accident Prevention - CIPA (a), Laboratory of Effort Physiology (b), Library - consultation collection room (c), Laboratory of Maternal and Child Nursing - LABEMI (d), Laboratory of Dietetic Technique (e), Laboratory of Semiology 2 and Clinical Evaluation (f), Nutrition Center (g), Library - study hall of the ground floor (h).

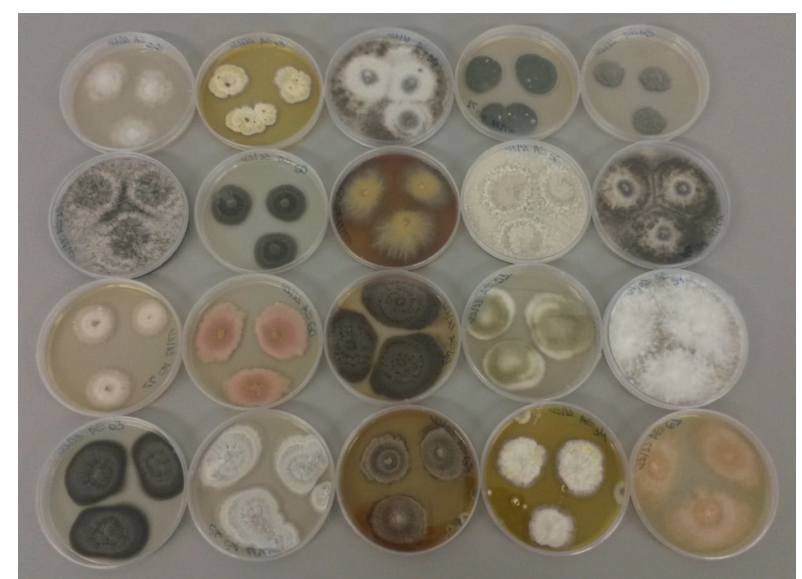

Figure 2 - Diversity of colonies after purification of fungi isolates from different environments of the Vitória Academic Center - UFPE/CAV.

legislation that establishes the absence of pathogenic and toxigenic fungi in indoor air.

Our study, Aboul-Nasr et al. (2013) found fungi isolated from unit intensive care unit hospital in India, 79 isolates were tested by thin layer chromatography (TLC) and at least one mycotoxin was these 79 isolates. Several mycotoxins are detected by TLC, the aflatoxins being zearalenone, gliotoxin, fumigiline, Mycotoxin production is a virulence factor.

The frequency of the fungal genera found in the analyzed environments, whose were: Aspergillus (50\%), Penicillium (21\%), Talaromyces (14\%), Curvularia and Paecilomyces (7\% each) as shown in Figure 4.

Anemophilous fungal infections in the medical literature and inhaled airborne spores have been implicated responsible for various allergic (Furtado and Ferraroni 1982). In addition to allergy, many opportunistic fungi such as those shown in Figure 4 , are responsible for diseases otitis, mycotoxicosis, urinary infections, onychomycosis, eye infections fungemia. Since are dispersed abundantly in the environment (Grumach 2001). Therefore, monitoring the environment detect potential 


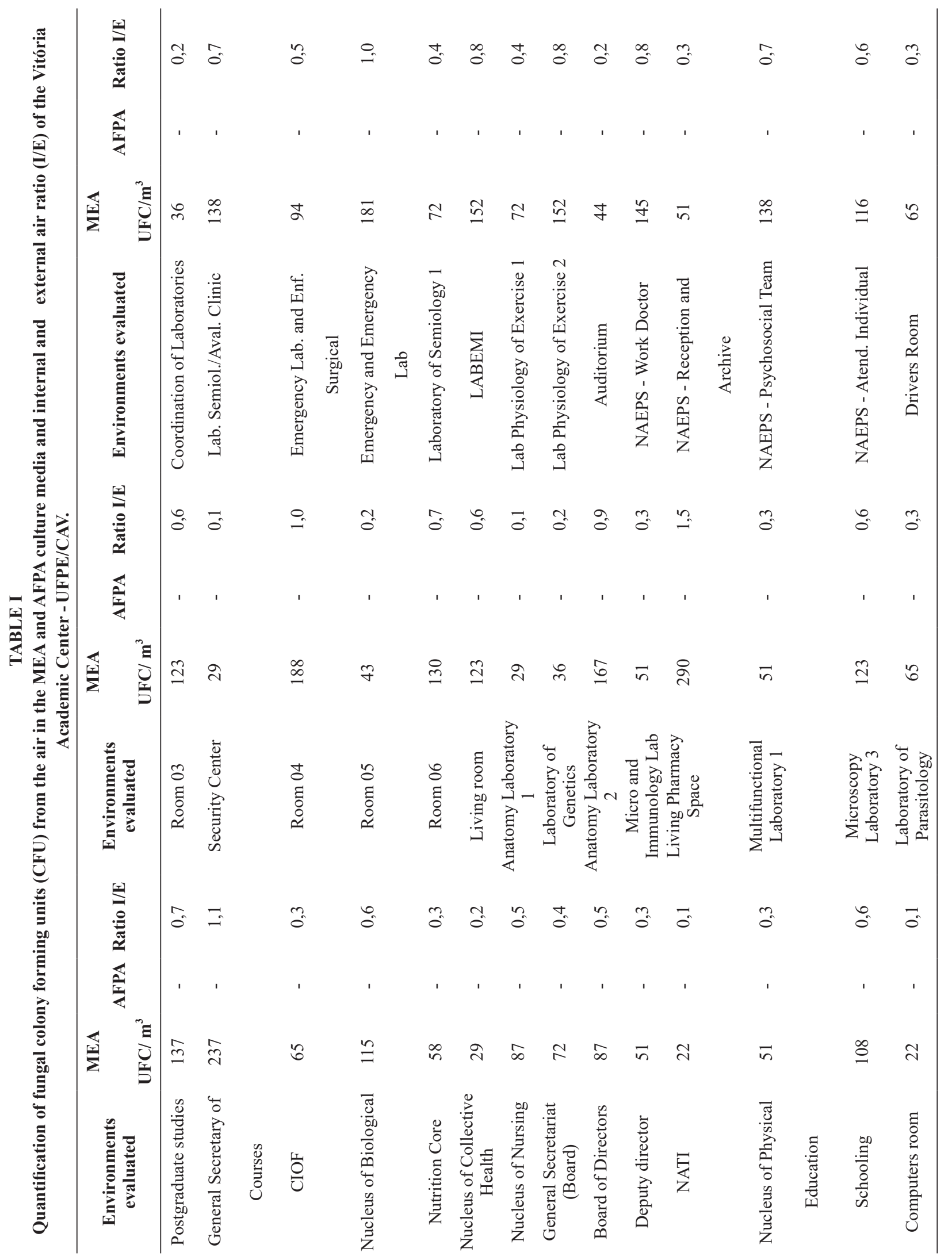




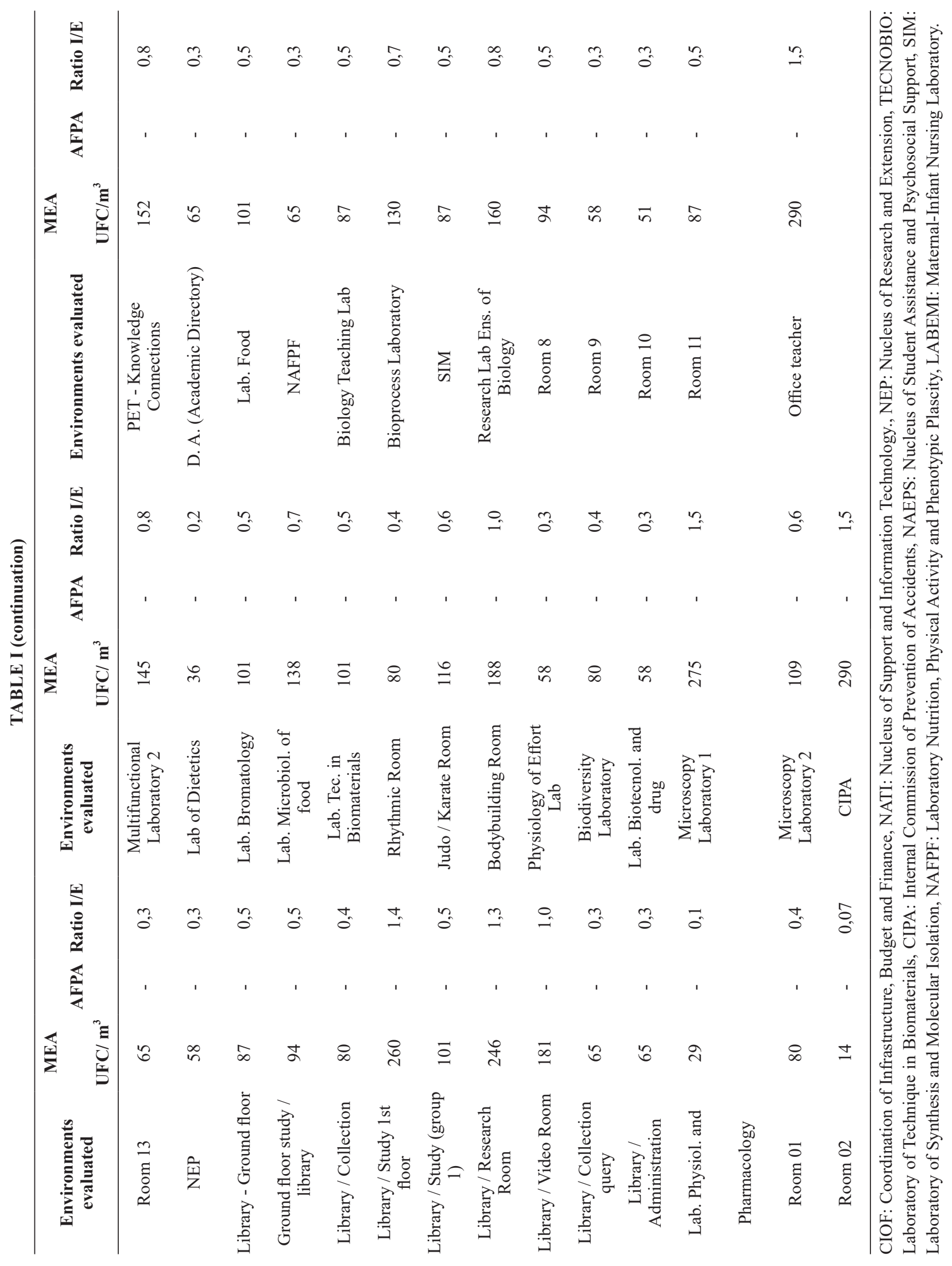




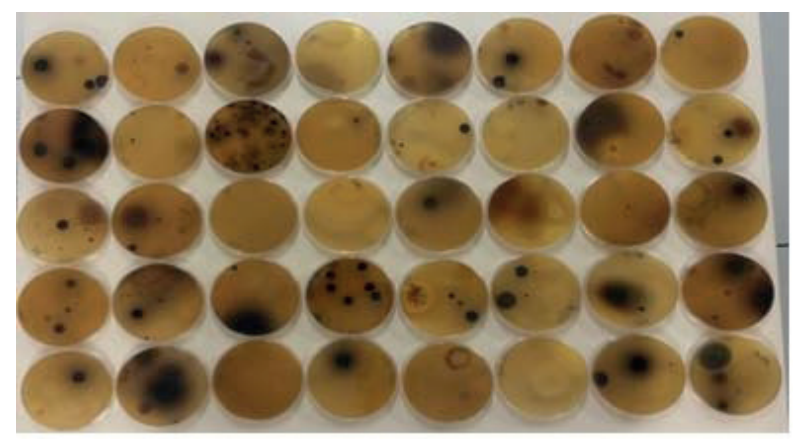

Figure 3 - Negative detection of aflatoxigenic fungi in CAV air in AFPA medium (absence of orange color on reverse of fungal colonies).

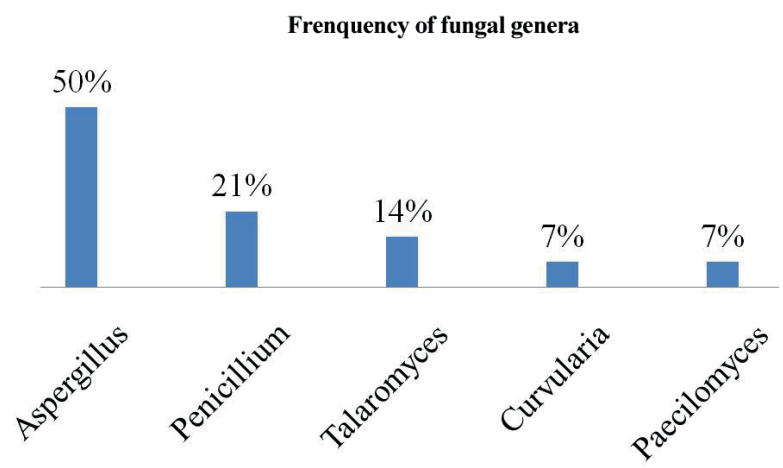

Figure 4 - Frequency of fungal genera found in the air of the analyzed environments of the CAV.

pathogenic prevent epidemics and protect public detect microorganisms (Zhoug et al. 2000).

Biologically, fungi are considered a promising source for new biomolecules with diverse biological activities for enzyme production and antimicrobial activity, due to chemical and structural diversity (Silva et al. 2015).

The majority of studies air quality were performed in hospital settings. Azimi et al. (2013) analyzed the quality of hospital air and found $70 \%$ of the samples fungi of Penicillium sp., 14\% Aspergillus sp., 12\% Cladosporium sp., 25\% Alternaria sp., indicating a risk factor for patients and professional these environments. Our study, since in addition to the analyzed environment being different, the most frequent was Aspergillus.

Library are similar with the study by Nascimento (2011) that when analyzing the internal air quality of the public library of the city of São Carlos/SP, did not find irregularities that would confront ANVISA legislation.

The CAV classrooms had values below 750 $\mathrm{CFU} / \mathrm{m}^{3}$, the results of this study differ from those presented by Morais (2010) who the microbiological quality of air in classrooms of a higher education institution, that $51 \%$ of the classrooms presented higher contamination than ANVISA.

Stryjakowska-Sekulska et al. (2007) studied nine environments at the University of Poznan in Poland. Chemistry laboratory, library, canteen, restrooms and board. All environments were evaluated morning and afternoon, 2 years. In the afternoon, possibly due to attending these environments throughout the day. They observed the following fungal genera in order of prevalence in the environments: Cladospirium sp., Penicillium sp., Aspergillus sp., Alternaria sp., Mucor sp., Rhizopus sp. and Epicocum sp. This result is in, since Aspergillus and Penicillium were also the most frequent genera the CAV according to Agarwal and Chakrabarti (2010) these genera as well as are the first colonizers of surfaces and interiors.

Pantoja et al. (2007) studied five sites (classroom, central library, warehouse, food court of the Campus of the State University of Ceará, Campus Itaperi. Among the 18 genera isolated from the evaluated environments, the most commonly found were Aspergillus sp. (78\%),

Penicillium sp. (30\%) and Fusarium sp. $(22 \%)$. Classroom and central library indicating the importance of human activity as the main influencing factor of mycobiota contamination in these environments.

It is noteworthy that Pantoja et al. (2007) found fungal genera because the collection method, although it was passive sedimentation, stratified the air collection time generally recommended in the world literature, which is $15 \mathrm{~min}$, and the samples were collected for $12 \mathrm{~h}$. 
The concern to find the genus Aspergillus and Penicillium in indoor and air-conditioned environments is species these genera produce secondary metabolites with a toxic effect on health (Peluque 2014). Exposure to mycotoxins may lead to reactions including hemorrhages and necrosis, and in abundance such toxins have affinity for specific organs or tissues such as the liver, kidneys and nervous system (IARC 2002).

Kalwasinska et al. (2012) evaluated functional and nonfunctional environments of a university library in Torun, Poland. According to the authors, the internal air was according to the legislation, both in the functional (classroom, reading room of periodicals, collection conservation salt), in nonfunctional (bathroom, cafeteria) in which all sectors of the CAV library analyzed were below the limit established by ANVISA (Table I).

Boff (2011) environments with fungal agglomerates influenced by environmental factors such as temperature, humidity, airflow, available organic substrates, climatic conditions and seasonal variation, physical factors the shape, size and density of the particles, among other situations that corroborate the increase of conidia in the environment.

Ejdys et al. (2013) studied the fungal composition of air from school classrooms and monitored or years, classifying according to biosafety level. The authors isolated 151 species of fungi, of which 22 and 61 species of fungi were classified as class 1 of biological risk.

Hayleeyesus and Manaye (2014) studied university from Ethiopia and observed that the according to the legislation, with concentrations of fungi ranging from 367 to $2.595 \mathrm{CFU} / \mathrm{m}^{3}$. Aspergillus sp., Penicillium sp., Alternaria sp., Cladosporium sp. and Fusarium sp. most frequently found found for the library and other environments of the CAV.

Many fungal species, including those present in the air, may be responsible for the production of metabolites with the most varied industrial and biological applications, enzymatic and antimicrobial activities (Viriato 2014).

The sources of extraction to study biological activities are soil, water, plants and more recently marine environments, exploring the secondary metabolism in order to perform tests using liquids and metabolic extracts or isolated metabolites by chromatography. The existing fungi in atmospheric air containing a range of pollutants still unexplored for the isolation of fungi some biological activity.

From the air, 67 specimens were initially isolated and then tested with 14 isolates after morphological identification to determine the enzymatic activity for the production of amylase, lipase and protease. The species of filamentous fungi identified in the air of the CAV were Paecilomyces variotti Bainier (04), P. fellutanum Biourge (06), Aspergillus flavus Link (09), A parasiticus Speare (14, 20, 27 and 67), A. sydowii (Bainier \& Sartory) Thom \& Church (18),

Talaromyces purpureogenus Samson, Yilmaz, Houbraken, Spierenb., Seifert, Peterson, Varga \& Frisvad (21 and 28), A. japonicas Saito (24), Penicillium oxalicum Currie \& Thom (25), P. chrysogenum Thom (26) and Curvularia lunata (Wakker) Boedijn (49) (Table II).

Among the species tested for enzymatic activity, A. sydowii presented better results for production of amylase $(6 \mathrm{~mm})$, lipase $(14 \mathrm{~mm})$ and protease $(5 \mathrm{~mm})$. Two other species produced the three enzymes (A. parasiticus Speare and $P$. fellutanum Biourge), but with less activity. Only three isolates belonging to three species were negative for the three enzymes simultaneously, namely: P. variotii Bainier (04), A. parasiticus Speare (20) and C. lunata (Wakker) Boedijn (49).

Not all isolates of a fungal species necessarily have the same enzyme the same intensity. Therefore our study that although the isolates 14, 27 and 67 belong to the same species Aspergillus parasiticus Speare, the same enzymatic reaction 
was not observed among them. For, the isolate 27 only produced lipase and the isolates 14 and 67 produced all three enzymes, results the isolates of Talaromyces purpureogenus Samson, Yilmaz, Houbraken,

Spierenburg, Seifert, Peterson, Varga \& Frisvad. The fungi species that presented the best amiolitic activities were Penicillium fellutanum Biourge $(7 \mathrm{~mm})$ and $P$. Oxalicum Currie \& Thom $(7$ $\mathrm{mm}$ ) and lipase activity were Aspergillus parasiticus Speare $(10 \mathrm{~mm})$ and $A$. sydowii (Bainier \& Sartory) Thom \& Church $(14 \mathrm{~mm})$. The production of protease, although the one of lower intensity for the producing species, had the isolate 18 of $A$. sydowii (Bainier \& Sartory) Thom \& Church as the best producer $(5 \mathrm{~mm}) \quad$ (Table III). The intensity of the in solid substrate can be directly influenced the solubility, diffusibility, enzyme, other factors.

The results presented in this study show that amiolytic activity was the most common among the species, corroborating with the finding of Wenzel et al. (2013) evaluated endophytic fungi of soybean and revealed a greater quantitative enzymatic activity for the amylase $(83.3 \% 20)$.

The amylase reaction halos in our study varied between 4 and $7 \mathrm{~mm}$ the results found by Firmino and Furtado (2014) the fungus Ceracystis sp., whereas Tavares et al. (2012) $29 \mathrm{~mm}$ halos evaluating Aspergillus isolated from noni (Morinda citrifolia L.).

A study by Soares et al. (2010) for amylase production, suggest that fungi under stress conditions interfere with enzymatic production. Firmino and Furtado (2014) also evaluated lipase activity with isolates of the fungus Ceracystis sp. did not observe any activity for this enzyme. The authors also tested the protease and halos did not exceed $1 \mathrm{~mm}$.

The averages of enzymatic activities of our study differ from the results presented by Griebeler et al. (2015) who found higher values halos above $7.08 \mathrm{~mm}$ for amylase, lipase and protease. These
TABLE II

Identification of the species of the fungi isolated in the air of the CAV/UFPE.

\begin{tabular}{cc}
\hline $\begin{array}{c}\text { Identification of species of } \\
\text { filamentous fungi }\end{array}$ & $\begin{array}{c}\text { Identification code of the } \\
\text { fungal isolate }\end{array}$ \\
\hline Paecilomyces variotti & $(04)$ \\
Penicillium fellutanum & $(06)$ \\
Aspergillus flavus & $(09)$ \\
Aspergillus parasiticus & $(14),(20),(27)$ and (67) \\
Aspergillus sydowii & $(18)$ \\
Talaromyces purpurogenus & $(21)$ and (28) \\
Aspergillus japonicus & $(24)$ \\
Penicillium oxalicum & $(25)$ \\
Penicullium chrysogenum & $(26)$ \\
Curvularia lunata & $(49)$ \\
\hline
\end{tabular}

authors worked with isolated fungi from different sources, such as soil, olive and soybean oil, cheeses, tomato extract, cream of milk, meat, soybean meal and contaminated culture media.

A study evaluated fungi isolated Baru seeds, bark and pulp (Dipteryx alata Vog.) and observed that none of the fungi had proteolytic activity, but all of them were able to present some amiolytic and lipolytic activity (Molina et al. 2012). The evaluation performed by Bezerra et al. (2012) with isolates of a Caatinga plant (Opuntia ficus$\mathrm{Mil}$ ) revealed that a strain of $A$. japonicas Saito did not produce proteolytic activity, corroborating with our study. Sunitha et al. (2013) enzymatic production differs among fungi and is related to the habitat where it is found.

Aboul-Nasr et al. (2013) tested 110 fungal isolates from intensive care unit air and hospital operating room in India and found that among the 110 isolates tested, $73 \%$ produced protease, lipase and urease, and this was the only the literature testing the enzymatic and mycotoxin production potential of anemophilous fungi. Among the lipase and protease isolates were Aspergillus sp., Cladosporium sp., Myrothecium sp. and Fusarium sp. According to the authors, these results are important since proteases and lipases play a role 
TABLE III

Identification of the species and metabolic product of fungi isolated in the air of the CAV/UFPE and halo of enzymatic activity (in mm).

\begin{tabular}{|c|c|c|c|c|}
\hline \multicolumn{2}{|c|}{ Species and metabolic } & \multicolumn{3}{|c|}{$\begin{array}{l}\text { Halo and enzymatic activity } \\
\text { (in } \mathrm{mm} \text { ) }\end{array}$} \\
\hline Code & product & $\mathbf{A}$ & $\mathbf{L}$ & $\mathbf{P}$ \\
\hline 04 & $\begin{array}{c}\text { Paecilomyces } \\
\text { variotti }\end{array}$ & - & - & - \\
\hline 06 & $\begin{array}{l}\text { Penicillium } \\
\text { fellutanum }\end{array}$ & $+(7 \mathrm{~mm})$ & $+(5 \mathrm{~mm})$ & $+(1 \mathrm{~mm})$ \\
\hline 09 & Aspergillus flavus & $+(6 \mathrm{~mm})$ & - & - \\
\hline 14 & $\begin{array}{l}\text { Aspergillus } \\
\text { parasiticus }\end{array}$ & $+(5 \mathrm{~mm})$ & $+(10 \mathrm{~mm})$ & $+(2 \mathrm{~mm})$ \\
\hline 18 & Aspergillus sydowii & $+(6 \mathrm{~mm})$ & $+(14 \mathrm{~mm})$ & $+(5 \mathrm{~mm})$ \\
\hline 20 & $\begin{array}{l}\text { Aspergillus } \\
\text { parasiticus }\end{array}$ & - & - & - \\
\hline 21 & $\begin{array}{l}\text { Talaromyces } \\
\text { purpurogenus }\end{array}$ & $+(4 \mathrm{~mm})$ & $+(6 \mathrm{~mm})$ & - \\
\hline 24 & $\begin{array}{l}\text { Aspergillus } \\
\text { japonicus }\end{array}$ & - & $+(2 \mathrm{~mm})$ & - \\
\hline 25 & Penicillium oxalicum & $+(7 \mathrm{~mm})$ & - & $+(1 \mathrm{~mm})$ \\
\hline 26 & $\begin{array}{l}\text { Penicullium } \\
\text { chrysogenum }\end{array}$ & $+(6 \mathrm{~mm})$ & - & $+(4 \mathrm{~mm})$ \\
\hline 27 & $\begin{array}{l}\text { Aspergillus } \\
\text { parasiticus }\end{array}$ & - & $+(3 \mathrm{~mm})$ & - \\
\hline 28 & $\begin{array}{l}\text { Talaromyces } \\
\text { purpurogenus }\end{array}$ & $+(7 \mathrm{~mm})$ & - & - \\
\hline 49 & Curvularia lunata & - & - & - \\
\hline 67 & $\begin{array}{l}\text { Aspergillus } \\
\text { parasiticus }\end{array}$ & $+(5 \mathrm{~mm})$ & $+(4 \mathrm{~mm})$ & $+(2 \mathrm{~mm})$ \\
\hline
\end{tabular}

(Code) Identification code of fungal isolate, $(\mathrm{mm})$ Millimeter, (A) Amylase, (L) Lipase, (P) Protease, (+) Produced enzymatic activity, (-) It did not produce enzymatic activity.

during microbial infection and suggest these results are important since the extracellular lipases play an important role during microbial infection, since they digest lipids to obtain nutrients by pathogenic microbes, allowing the growth of microbes where lipids are the only source of carbon and proteolytic degradation of lung tissues has been identified as a key phenomenon in the pathophysiology of Aspergillus fumigatus, several species of Aspergillus secrete protease.
In relation to the tests of antibacterial activity of the fungi isolated from the air of the CAV, three metabolic liquids presented activity against all bacteria tested, represented by the species Paecilomyces variotii Bainier (04), Talaromyces purpureogenus Samson, Yilmaz, Houbraken, Spierenb., Seifert, Peterson, Varga \& Frisvad (28) and Aspergillus parasiticus Speare (67). The metabolic liquid of Curvularia lunata (Wakker) Boedijn (49) no antibacterial activity against the bacteria tested (Table IV).

The metabolic liquid of the species Talaromyces purpureogenus Samson, Yilmaz, Houbraken, Spierenburg, Seifert, Peterson, Varga \& Frisvad (isolate 28) presented the best antibacterial activity against all the bacteria tested, reaching the of $125 \mu \mathrm{L} / \mathrm{mL}$, none of the metabolic liquids tested presented bactericidal action, only bacteriostatic.

Duarte (2006) reports that no consensus what is acceptable the level of inhibition for antimicrobial activity related to natural products versus standard antibioticssome authors consider only antibioticlike results, although others understand that levels inhibition good potential.

The study by Paraginskia et al. (2014) analyzed all bacterial strains evaluated in our study, but used different concentrations of triazenes compounds for antimicrobial activity and obtained bacteriostatic action in at least one of the six evaluated compounds.

\section{CONCLUSIONS}

It was concluded that the environments analyzed in the UFPE/CAV presented great diversity of fungi species they met the requirements of the ANVISA resolution. It was also verified that not present fungi potentially harmful to human health in the environments. Our study demonstrated that some species of anemophilous filamentous fungi are capable of producing the amylase, lipase and 
TABLE IV

Minimum inhibitory Concentration of the antibacterial activity of the isolated fungi species in the CAV/UFPE air.

\begin{tabular}{|c|c|c|c|c|c|c|c|c|}
\hline \multirow{2}{*}{$\begin{array}{c}\text { Species and } \\
\text { Metabolic Product }\end{array}$} & \multicolumn{8}{|c|}{$\begin{array}{l}\text { Metabolic Fungus Product } \\
\text { Lower Inhibitory Minimum Concentration }(\mu \mathrm{L} / \mathrm{mL})\end{array}$} \\
\hline & 01 & 02 & 03 & 04 & 05 & 06 & 07 & 08 \\
\hline Paecilomyces & + & + & + & + & + & + & + & + \\
\hline variotti (04) & $(500)$ & $(500)$ & $(500)$ & $(250)$ & $(500)$ & $(500)$ & $(500)$ & $(500)$ \\
\hline Aspergillus & + & + & + & + & - & + & + & - \\
\hline japonicus (24) & $(500)$ & $(500)$ & $(500)$ & $(250)$ & & $(500)$ & $(500)$ & \\
\hline Talaromyces & + & + & + & + & + & + & + & + \\
\hline purpurogenus (28) & $(250)$ & $(125)$ & $(125)$ & $(125)$ & $(250)$ & $(125)$ & $(125)$ & $(250)$ \\
\hline \multicolumn{9}{|l|}{$(49)$} \\
\hline Aspergillus & + & + & + & + & + & + & + & + \\
\hline parasiticus (67) & $(500)$ & $(500)$ & $(500)$ & $(250)$ & $(500)$ & $(500)$ & $(250)$ & $(500)$ \\
\hline
\end{tabular}

protease enzymes the fungi Aspergillus parasiticus Speare and A. sydowii (Bainier \& Sartory) Thom $\&$ Church better amiolytic potential among the other species and enzymes under the conditions of this experiment. The antimicrobial activity of the species Talaromyces purpureogenus Samson, Yilmaz, Houbraken, Spierenburg, Seifert, Peterson, Varga \& Frisvad was the one that presented the best result however, showed low bactericidal potential.

\section{REFERENCES}

ABOUL-NASR MB, ABOUL-NASER AZ AND AMER EM. 2013. Enzymatic and toxigenic ability of opportunistic fungi contaminating intensive care units and operation rooms at Assiut University Hospitals, Egypt. SpringerPlus 2(347).

AGARWAL R AND CHAKRABARTI A. 2010. Epidemiology of allergic bronchopulmonary Aspergillosis. In: Pasqualotto AC (Ed), Aspergillosis: from diagnosis to prevention. New York: Springer Science. Biomed Life Sci, p. 671-688.

ARAÚJO R AND CABRAL JP. 2010. Fungal air quality in medical protected environments. In Kumar A (Ed). Air Quality, p. 357-382.

AZIMI F, NADDAFI K, NABIZADEH R, HASSANVAND MS, ALIMOHAMMADI M, AFHAMI S AND MUSAVI SN. 2013. Fungal air quality in hospital rooms: a case study in Tehran, Iran. J Environ Health Sci Eng 11(30): $1-4$.

BEZERRA JDP, SANTOS MGS, SVEDESE VM, LIMA DMM, FERNANDES MJS, PAIVA LM AND SOUZAMOTTA CM. 2012. Richness of endophytic fungi isolated from Opuntia ficus- indica Mill. (Cactaceae) and preliminary screening for enzyme production. World J Microb Biot 28(5): 1989-1995.

BOFF C. 2011. Monitoring fungi in the air of intensive care units. 61p. Dissertation (Master's Degree in Pneumological Sciences) - Faculty of Medicine. Federal University of Rio Grande do Sul, Porto Alegre. (Unpublished).

BRAZIL. 2003. Ministry of Health. National Agency of Sanitary Surveillance (ANVISA). Methodology of Sensitivity Tests to Dilution Antimicrobial Agents for Aerobic Growth Bacteria. Approved Standard M7-A6, 6th ed. 23(2): 1-81.

CATÃO RMR, NUNES LE, VIANA APP, ROCHA WRV AND MEDEIROS ACD. 2014. Antibacterial activity and interactive in vitro effect of a cranberry product on Escherichia coli. Rev Ciênc Basic Farm Apl 35(4): 723729.

DUARTE MCT. 2006. Antimicrobial activity of medicinal and aromatic plants used in Brazil. Rev Multiciência 7: $1-16$.

EJDYS E, DYNOWSKA M, BIEDUNKIEWICZ A AND SUCHARZEWSKA E. 2013. An Overview of the Species of Fungi Occurring in School Rooms - a Four-Year Study. Pol J Environ Stud 22(6): 1691-1700. 
FIRMINO AC AND FURTADO EL. 2014. Production of extracellular enzymes by Ceratocystis spp. Summa Phytopathol 40(4): 371-374.

FRIBERG B ET AL. 1999. Correlation between surface and air count of particles carrying bacteria in operating rooms with turbulent ventilation. J Hosp Infect 42: 61-68.

FURTADO MSS AND FERRARONI JJ. 1982. Anemophilous fungi in hospital environments of the city of Manaus, Amazonas, Brazil. Sci Cult 34(12): 1642-1647.

GRIEBELER NE, BORTOLI V, ASTOLFI AL, DARONCH NA, SCHUMANN AC, SALAZAR LN, CANSIAN RL, BACKES GT AND ZENI J. 2015. Selection of filamentous fungi producing amylases, proteases, cellulases and pectinases. Rev Acad Ciênc Anim 13: 15-24.

GRUMACH AS. 2001. Allergy and immunology in childhood and adolescence. São Paulo: Atheneu, p. 16-21.

HAYLEEYESUS SF AND MANAYE AM. 2014. Microbiological Quality of Indoor Air in University Libraries. Asian Pac J Trop Biomed 4(1): S312-S317.

IARC - INTERNATIONAL AGENCY FOR RESEARCH ON CANCER. 2002. Some traditional herbal medicine, some mycotoxins, naphthalene and styrene. IARC Monograph Eval. Carcinog. Risks Human 82: 1-556.

KALWASIŃSKA A, BURKOWSKA A AND WILK I. 2012. Microbial air contamination in indoor environment of a university library. Ann Agric Environ Med 19(1): 25-29.

LACAZ CS ET AL. 1998. Guide for identification of fungus actinomycetes and algae of medical interest, 8th ed., São Paulo: Sarvier, $445 \mathrm{p}$.

MENEZES M AND HANLIN SMP. 2004. Practical guide to phytopathogenic fungi. 2nd ed., Recife, PE. University Press, UFRPE.

MOLINA G, PIMENTEL MR, BERTUCCI TCP AND PASTORE GM. 2012. Application of fungal endophytes in biotechnological processes. Chem Eng Trans 27: 289-294.

MORAIS GR, SILVA MA, CARVALHO MV, SANTOS JGS, DOLINGER EJOV AND BRITO DVD. 2010. Indoor air quality in a Brazilian higher education institution. Biosci J 26: 305-310.

NAGARAJAN S. 2012. New tools for exploring old friendsmicrobial lípases. Appl Biochem Biotechnol 168(5): 11631196.

NASCIMENTO GC. 2011. Evaluation of air quality in indoor environments: public library. 170 p. Dissertation (Master in Hydraulics and Sanitation) - University of São Paulo, School of Engineering of São Carlos, São Carlos. (Unpublished).

OLIVEIRA LDC AND BORGES PALUCHA LR. 2015. Respiratory allergies: a review of the main anemophilous fungi and triggering factors. RBSP 39(2): 426-441.

PANTOJA LDM, COUTO MS AND PAIXÃO GC. 2007. Diversity of bioaerosols present in urbanized and preserved environments of a university campus. Biological, São Paulo 69(1): 41- 47.

PARAGINSKIA GL, BERTICELLIA CR, ZAMBIAZIA PJ, PARAGINSKIA VTK, HÖRNERA M, SANTOS AJRWA AND HÖRNERC R. 2014. In vitro antibacterial activity and toxicity to Artemia saline Leach. of some triazenes compounds. Chem New 37(7): 1138-1144.

PELUQUE E. 2014. Isolation, molecular identification and toxigenic potential of fungi and occurrence of mycotoxins in mixtures of cereals marketed in Brazil. 80 p. Dissertation (Master in Food Engineering) - Faculty of Zooctenia and Food Engineering, University of São Paulo, São Paulo. (Unpublished).

RAHMAN M, KÜNHN I, RAHMAN M, OLSSONLILJEQUIST B AND MÖLLBY R. 2004. Evaluation of a scanner-assisted colorimetric MIC method for susceptibility testing of gram- negative fermentative bacteria. Appl Environ Microbiol 70(4): 2398-2403.

REINEHR CO, RIZZARDI J, SILVA MF, OLIVEIRA D, TREICHEL H AND COLLA LM. 2014. Production of lipases of Aspergillus niger and Aspergillus fumigatus through solid state fermentation, evaluation of substrate specificity and its use in esterification and alcohololysis reactions. Chem New 37(3): 454-460.

RIDDELL RW. 1950. Permanent staired mycological preparation sobtained by slide culture. Mycology 42: 265-270.

SAMSON RAAND FRISVAD JC. 2004. Penicillium subgenus Penicillium: new Taxonomics Schemes, Mycotoxins and Other Extrolites. Stud Mycol 49: 257.

SANTOS LA, MENEZES JS, RUFINO LRA, OLIVEIRA NMS AND FIORINI JE. 2014. Determination of the antimicrobial activity of the hydroalcoholic extract of the plant Plectranthus ornatus codd (Bilberry Chinese). Rev Univ Vale do Rio Verde 12(1): 119-129.

SILVA EB, OHARA A, FERNANDES CM, BARBOSA PPM AND MACEDO GA. 2015. Screening of filamentous fungi from Brazilian rainforests for enzyme production. Afr J Microbiol Res 9(5): 332-342.

SOARES IA ET AL. 2010. Identification of the amylolytic potential of mutant strains of the filamentous fungus Aspergillus nidulans. Ciênc Tecnol Food 30(3): 700705.

STRYJAKOWSKA-SEKULSKA M, PIOTRASZEWSKAPAJAK A, SZYSZKA A, NOWICKI M AND FILIPIAK M. 2007. Microbiological Quality of Indoor Air in University Rooms. Polish J Environ Stud 16(4): 623632.

SUNITHA VH, DEVI NIRMALA D AND SRINIVAS C. 2013. Extracelullar enzymatic activity of endophytic fungal strains isolated from medicinal plants. World J Agric Sc 9(1): 1-9.

TAVARES ACD, FONSECA JS, FONSECA TRB, BARRONCAS JF, SOUZA RAT, SILVA TA AND 
TEIXEIRA MFS. 2012. Extracellular enzymes of anamorphic fungi isolated from Morinda Citrifolia L. Biochem Biotecnol Rep 1(2): 1-6.

VIRIATO A. 2014. Terpenoids with antifungal activity for Candida Berkhout, causing nosocomial infections. World Health 38(1): 40-50.

WENZEL JB ET AL. 2013. Enzymatic and antimicrobial activity of endophytic fungi isolated from soybean. Pesq. Online: Biol and Health 9(3): 1-15.

ZHOUG G, WHONG WZ, ONG T AND CHEN B. 2000. Development of a fungus-specific PCR assay for detecting low-level fungi in a indoor environment. Mol Cell Probes 14: 339-348.

\section{ERRATA}

In the article 'Antimicrobial and enzymatic activity of anemophilous fungi of a public university in Brazil', with DOI number: http:// dx.doi.org/10.1590/0001-3765201720160903, published in the journal Anais da Academia Brasileira de Ciências, 89(3 Suppl.): 2327-2340. Page 2327:

\section{Reads:}

\section{ABSTRACT}

To the fungal microbiota the UFPE and biotechnological potential enzymatic and antimicrobial production. Air conditioned environments were sampled using a passive sedimentation technique, the air I ratio and the presence of aflatoxigenic strains evaluated for ANVISA. Icelles were to determine the enzymatic activity of lipase, amylase and protease metabolic liquids to determine antimicrobial activity. Diversity was observed in all CAV environments, $\mathrm{CFU} / \mathrm{m}^{3}$ ranged from 14 to 290 and $\mathrm{I} / \mathrm{E}$ ratio from 0.1 to 1.5 . The of the fungal genera were: Aspergillus (50\%), Penicillium (21\%), Talaromyces (14\%), Curvularia and Paecilomyces (7\% each). Aspergillus sydowii (Bainier \& Sartory) Thom \& Church presented enzymatic activity and the Talaromyces purpureogenus Samson, Yilmaz, Houbraken, Spierenb., Seifert, Peterson, Varga
\& Frisvad presented antibacterial activity against all bacteria that all environments present fungal species biodiversity no toxigenic or pathogenic fungi were found, according to ANVISA legislation for conditioned environments and airborne filamentous fungi present potential for enzymatic and antimicrobial activity.

Key words: Air quality, bacteria, enzymes, filamentous fungi, refrigerated environments.

\section{INTRODUCTION}

Fungi air, water, soil, animals and food. They colonize substrates, have an extensive geographic distribution and are able to grow under environmental conditions (Oliveira and BorgesPaluch 2015).

Fungal contamination is considered due to the production. Of the filamentous fungi under adequate conditions of oxygen, temperature and humidity, secondary metabolites (mycotoxins) both and animals, fungi of the genus Aspergillus and Penicillium. A. flavus Link and A. parasiticus Speare produce aflatoxins (Peluque 2014).

Therefore, monitoring air in artificially airconditioned is according to Resolution RE No. 9 of January 16, 2003, the National Agency of Sanitary Surveillance (ANVISA), which defines reference standards cleaning and maintenance of the health and safety of individuals who attend public and collective places with conditioned environments. The recommended maximum acceptable contamination of $\leq 750 \mathrm{CFU} / \mathrm{m} 3$ and $\leq 1.5$ for the relation between internal and external air the presence of pathogenic and toxigenic fungi (Brazil 2003).

Biotechnically, microbial enzymes are by industries reduced production time, increased scale and purification, specificity and stabilization, as well as easy genetic manipulation (Nagarajan 2012) and high biochemical diversity (Silva et al. 2015) is related to the minimization production (Reinehr 
et al. 2014) and waste and electric consumption (Silva et al. 2015).

Dispersion and appearance of commercially available antimicrobial-resistant microbes, thus the search for sources of effective antimicrobial agents (Santos et al. 2014) researches with the purpose of intervening, preventing or intensifying the conventional bacterial resistance (Catão et al. 2014).

The antimicrobial using mycelia and liquid metabolites of anemophilous filamentous fungi this may be the first activity. The present study aimed to evaluate the microbiological quality of air, the presence of aflatoxigenic fungi in the climatic environments of the Federal University of Pernambuco/Vitória Academic Center and enzymatic production and antimicrobial activity.

\section{MATERIALS AND METHODS}

\section{SAMPLING AND COLLECTION OF AIR}

The study was conducted at the Federal University of Pernambuco/Vitória Academic Center (UFPE/ CAV) and 82 artificially air-conditioned 3 board of directors, 9 library, 1 auditorium, 15 classrooms, 34 laboratories, 13 administrative rooms, 1 room of the Internal Accident Prevention Commission (CIPA), 5 student assistance centers, 1 teaching staff and an external area located in the courtyard of the main entrance of the CAV for fungi quantification. Nonair-conditioned environments were excluded from the study.

The samples were collected from the central area of the environments through the passive sedimentation technique (Lacaz et al. 1998) on solid culture medium using Petri dishes containing the culture (MEA) and Aspergillus flavus and parasiticus agar (AFPA) for total and aflatoxigenic fungi cultures, respectively. The plates were placed $1 \mathrm{~m}$ the ground and opened for $15 \mathrm{~min}$ bioaerosols, containing microorganisms present in the atmospheric air. The plates were incubated at room temperature $\left(28 \pm 2^{\circ} \mathrm{C}\right)$ for up to days.

\section{MICROBIOLOGICAL ANALYSIS OF AIR}

The colonies present in the respective culture media were quantified and the relation between internal and external air (I/E) was calculated to determine the internal air quality. ANVISA the recommended maximum acceptable microbiological contamination value of $\leq 750 \mathrm{CFU} / \mathrm{m} 3$ and $\leq 1.5$ for the relationship between internal and external air (Brazil 2003).

Sedimentation sampling does not directly determine the number of microorganisms present in a given volume of airit is possible to transform the results of this method (number of CFU/unit area) into CFU/volume unit number (Morais et al. 2010). Air sampling by sedimentation was using the following equation described by Friberg et al. (1999):

The area of the petri dish $90 \times 15 \mathrm{~mm}$ (our study $0.006 \mathrm{~m}_{2}$ ). SAR is the ratio between the in the air and on the surface of the culture medium. For environments with spontaneous sedimentation and without apparatus that forces the sedimentation of air, this ratio is 1:23 (Morais et al. 2010).

\section{IDENTIFICATION OF AFLATOXIGENIC FUNGI}

The presence of aflatoxigenic strains revealed by the orange reverse of the AFPA culture medium was evaluated. ANVISA the presence of pathogenic and toxigenic fungi in artificially climatized environments (Brazil 2003).

ISOLATION, IDENTIFICATION AND PRESERVATION OF FUNGI

After in the MEA solid culture medium, the fungal colonies were purified in the same culture medium. After the fungal species, the macroscopic (coloration, appearance and diameter of the colonies) and microscopic (somatic and 
reproductive microstructures) (Samson and Frisvad 2004) were observed through culture under coveralls (Riddell 1950) and preserved to the Castelani method distilled water and immersion of pure cultures mineral oil. The samples were collected test tubes containing MEA solid culture medium in order to each species identified in the Collection of Cultures Micoteca URM of the Federal University of Pernambuco.

\section{DETERMINATION OF ENZYMATIC ACTIVITY}

To determine the enzymatic activity of the fungi isolated from the air, 14 species were identified according to the number attributed to the isolates [Paecilomyces variotti Bainier (04), Penicillium fellutanum Biourge (06), Aspergillus flavus Link (09), A. parasiticus Speare (14, 20, 27 and 67), A. sydowii (Bainier \& Sartory) Thom \& Church (18), Talaromyces purpureogenus Samson, Yilmaz, Houbraken, Spierenb., Seifert, Peterson, Varga \& Frisvad (21 and 28), Aspergillus japonicas Saito (24), Penicillium oxalicum Currie \& Thom (25), Penicullium chrysogenum Thom (26) and Curvularia lunata (Wakker) Boedijn (49)] for lipase, amylase and protease production, following the methodology Menezes and Hanlin (2004). Mycelial dis were from fungal colonies and peeled into the central area of the Petri dish containing culture media specific for each enzyme incubated for at room temperature. The tests were performed in triplicate for each culture medium.

The lipase reaction was by visualizing the presence of calcium salt crystals of lauric acid and/ or the formation of a clear area around the fungal colony dis. To the production of amylase, $0.1 \mathrm{~N}$ iodine solution was used, allowing the identification of the enzymatic reaction through a translucent halo around the colony. For protease, due to the chemical reaction it was possible to visualize the formation of translucent halo around the colony. After the development of the enzymatic reactions, a halo of enzymatic activity was measured to determine the production potential of the colonies, which is proportional to the halo diameter.

\section{DETERMINATION OF ANTIBACTERIAL ACTIVITY}

Of the species identified, 5 metabolic liquids from the species Paecilomyces variotti Bainier (04), Aspergillus japonicas Saito (24), Talaromyces purpureogenus Samson, Yilmaz, Houbraken, Spierenb., Seifert, Peterson, Varga \& Frisvad (28), Curvularia lunata (Wakker) Boedijn (49), Aspergillus parasiticus Speare (67) were randomly selected to perform antimicrobial activity and determine and purified fungal mycelia dis were cultured in $10 \mathrm{~mL}$ of liquid culture medium Sabouraud brothand incubated at room temperature for 20 days. The liquid metabolite was separated from the mycelium by filtration on sterile filter paper. The metabolic fluid was stored at $4{ }^{\circ} \mathrm{C}$ to perform the antibacterial activity tests and the mycelium was frozen for subsequent extraction of metabolites.

The strains of Gram-negative bacteria: Escherichia coli (ATCC 25922), Shigella flexneri (ATCC 12022), Salmonella typhimurium (ATCC 14028), Serratia marcescens, Klebsiella pneumoniae, Pseudomonas aeruginosa and Grampositive: Staphylococcus aureus (ATCC 29213) and S. aureus ORSA. The bacterial suspensions were prepared in $0.85 \%$ saline and a concentration of 1.5 $x 10{ }_{5} \mathrm{CFU} / \mathrm{mL}$ was obtained, from the dilution of the corresponding suspension to the 0.5 tube of the McFarland scale. Five metabolic liquids produced by filamentous fungi from atmospheric air were tested. All experiments were performed in triplicate. The antibacterial activity test was performed the broth dilution method of the ANVISAM7-A6 technical standard. Serial dilutions of metabolic liquids were performed. Positive control of the test was using chloramphenicol antibiotic and negative control of the test, in the absence of antibiotic, to 
confirm absences of contaminants in the metabolic liquid used in the test was added a column with the pure metabolic liquid. After distribution of the bacterial suspensions, the plates were incubated at $37^{\circ} \mathrm{C}$ for $24 \mathrm{~h} .20 \mu \mathrm{L} \mathrm{2,3,5-triphenyltetrazolium}$ chloride (TTC) $(2 \% \mathrm{v} / \mathrm{v})$ diluted in water was added to all wells after $2 \mathrm{~h}$ of incubation room temperature, bacterial growth. The wells stained in red indicate bacterial growth (Rahman et al. 2004).

The red coloration results from the TTC reaction with hydrogen ions constituted due to cellular respiration, generated by an insoluble reddish solution called formazan, indicating viable bacterial cells in the medium (Rahman et al. 2004).

The reading was performed through visual observation of the lowest concentration of metabolic liquids that inhibit bacterial growth. The test was performed, where was for Petri dishes containing Mueller-Hinton Agar, the plate incubated at $37^{\circ} \mathrm{C}$ for $24 \mathrm{~h}$. Bacterial growth, indicating bactericidal or bacteriostatic action of the fungal metabolic the wells not presentantimicrobial stained red.

The liquid metabolites used in the study were tested in their crude state after filtration. Therefore, the antimicrobial activity the inhibitory concentrations defined for the method in $\mu \mathrm{L} / \mathrm{mL}$ : $500.00 ; 250.00 ; 125.00 ; 62.50 ; 31.25 ; 15.63 ; 7.81$; $3.91 ; 1.95$ and $0.97 \mu \mathrm{L} / \mathrm{mL}$.

\section{RESULTS AND DISCUSSION}

Growth was observed in all environments the lowest amount of CFU/m3 in the classroom (14 $\mathrm{CFU} / \mathrm{m} 3$ ) and with the amount and diversity of the living pharmacy space, the CIPA room and the teaching office (Table I), all the evaluated environments of the CAV were within the ANVISA for microbiological air quality $(\leq 750 \mathrm{CFU} / \mathrm{m} 3)$. Fungal colonies from environments observed in Figures 1 and 2 the colonies before and after purification of the fungal isolates, respectively.
The evaluated environments possibly the access flow of ventilation and passers-by in the environments, atmosphere is influenced by the climate, the interior atmosphere is influenced by building maintenance. Both environments influence human activities, humidity and little temperature, since many indoor fungi grow in a wide temperature range (Araújo and Cabral 2010).

The ratio of fungi quantification of $\mathrm{I} / \mathrm{E}$ (internal/ external) of the environments surveyed in the CAV (Table I) met the current ANVISA legislation for air quality in conditioned environments $(\leq 1.5)$, this ratio 0.1 to 1.5 , the minimum and maximum, respectively, since the external air quantification was $188 \mathrm{CFU} / \mathrm{m} 3$.

The environments that presented an $\mathrm{I} / \mathrm{E}$ statement in the maximum acceptable limit were: library entrance hall, living pharmacy space, CIPA room and laboratory 1 and teaching room. Fact that the entrance hall of the library by visitors, with human activity showing a direct influence on the live pharmacy laboratory handles plant and soil samples CIPA room is an environment used for meetings the room is relatively frequented by students. In these environments, the values of the air fungi quantification in $\mathrm{CFU} / \mathrm{m} 3$ were allowed by ANVISA (750), but the I/E ratio was the limit.

No environment presented aflatoxigenic fungi (Figure 3) in compliance with the aforementioned legislation that establishes the absence of pathogenic and toxigenic fungi in indoor air.

Our study, Aboul-Nasr et al. (2013) found fungi isolated from unit intensive care unit hospital in India, 79 isolates were tested by thin layer chromatography (TLC) and at least one mycotoxin was these 79 isolates. Several mycotoxins are detected by TLC, the aflatoxins being zearalenone, gliotoxin, fumigiline, Mycotoxin production is a virulence factor.

The frequency of the fungal genera found in the analyzed environments, whose were: Aspergillus (50\%), Penicillium (21\%), Talaromyces (14\%), 
Curvularia and Paecilomyces (7\% each) as shown in Figure 4.

Anemophilous fungal infections in the medical literature and inhaled airborne spores have been implicated responsible for various allergic (Furtado and Ferraroni 1982). In addition to allergy, many opportunistic fungi such as those shown in Figure 4, are responsible for diseases otitis, mycotoxicosis, urinary infections, onychomycosis, eye infections fungemia. Since are dispersed abundantly in the environment (Grumach 2001). Therefore, monitoring the environment detect potential pathogenic prevent epidemics and protect public detect microorganisms (Zhoug et al. 2000).

Biologically, fungi are considered a promising source for new biomolecules with diverse biological activities for enzyme production and antimicrobial activity, due to chemical and structural diversity (Silva et al. 2015).

The majority of studies air quality were performed in hospital settings. Azimi et al. (2013) analyzed the quality of hospital air and found $70 \%$ of the samples fungi of Penicillium sp., 14\% Aspergillus sp., 12\% Cladosporium sp., 25\% Alternaria sp., indicating a risk factor for patients and professional these environments. Our study, since in addition to the analyzed environment being different, the most frequent was Aspergillus.

Library are similar with the study by Nascimento (2011) that when analyzing the internal air quality of the public library of the city of São Carlos/SP, did not find irregularities that would confront ANVISA legislation.

The CAV classrooms had values below 750 $\mathrm{CFU} / \mathrm{m} 3$, the results of this study differ from those presented by Morais (2010) who the microbiological quality of air in classrooms of a higher education institution, that $51 \%$ of the classrooms presented higher contamination than ANVISA.

Stryjakowska-Sekulska et al. (2007) studied nine environments at the University of Poznan in Poland. Chemistry laboratory, library, canteen, restrooms and board. All environments were evaluated morning and afternoon, 2 years. In the afternoon, possibly due to attending these environments throughout the day. They observed the following fungal genera in order of prevalence in the environments: Cladospirium sp., Penicillium sp., Aspergillus sp., Alternaria sp., Mucor sp., Rhizopus sp. and Epicocum sp. This result is in, since Aspergillus and Penicillium were also the most frequent genera the CAV according to Agarwal and Chakrabarti (2010) these genera as well as are the first colonizers of surfaces and interiors.

Pantoja et al. (2007) studied five sites (classroom, central library, warehouse, food court of the Campus of the State University of Ceará, Campus Itaperi. Among the 18 genera isolated from the evaluated environments, the most commonly found were Aspergillus sp. (78\%),

Penicillium sp. (30\%) and Fusarium sp. $(22 \%)$. Classroom and central library indicating the importance of human activity as the main influencing factor of mycobiota contamination in these environments.

It is noteworthy that Pantoja et al. (2007) found fungal genera because the collection method, although it was passive sedimentation, stratified the air collection time generally recommended in the world literature, which is $15 \mathrm{~min}$, and the samples were collected for $12 \mathrm{~h}$.

The concern to find the genus Aspergillus and Penicillium in indoor and air-conditioned environments is species these genera produce secondary metabolites with a toxic effect on health (Peluque 2014). Exposure to mycotoxins may lead to reactions including hemorrhages and necrosis, and in abundance such toxins have affinity for specific organs or tissues such as the liver, kidneys and nervous system (IARC 2002).

Kalwasinska et al. (2012) evaluated functional and nonfunctional environments of a university library in Torun, Poland. According to the authors, the internal air was according to the legislation, 
both in the functional (classroom, reading room of periodicals, collection conservation salt), in nonfunctional (bathroom, cafeteria) in which all sectors of the CAV library analyzed were below the limit established by ANVISA (Table I).

Boff (2011) environments with fungal agglomerates influenced by environmental factors such as temperature, humidity, airflow, available organic substrates, climatic conditions and seasonal variation, physical factors the shape, size and density of the particles, among other situations that corroborate the increase of conidia in the environment.

Ejdys et al. (2013) studied the fungal composition of air from school classrooms and monitored or years, classifying according to biosafety level. The authors isolated 151 species of fungi, of which 22 and 61 species of fungi were classified as class 1 of biological risk.

Hayleeyesus and Manaye (2014) studied university from Ethiopia and observed that the according to the legislation, with concentrations of fungi ranging from 367 to $2.595 \mathrm{CFU} / \mathrm{m} 3$. Aspergillus sp., Penicillium sp., Alternaria sp., Cladosporium sp. and Fusarium sp. most frequently found found for the library and other environments of the CAV.

Many fungal species, including those present in the air, may be responsible for the production of metabolites with the most varied industrial and biological applications, enzymatic and antimicrobial activities (Viriato 2014).

The sources of extraction to study biological activities are soil, water, plants and more recently marine environments, exploring the secondary metabolism in order to perform tests using liquids and metabolic extracts or isolated metabolites by chromatography. The existing fungi in atmospheric air containing a range of pollutants still unexplored for the isolation of fungi some biological activity.

From the air, 67 specimens were initially isolated and then tested with 14 isolates after morphological identification to determine the enzymatic activity for the production of amylase, lipase and protease. The species of filamentous fungi identified in the air of the CAV were Paecilomyces variotti Bainier (04), P. fellutanum Biourge (06), Aspergillus flavus Link (09), A. parasiticus Speare (14, 20, 27 and 67), A. sydowii (Bainier \& Sartory) Thom \& Church (18),

Talaromyces purpureogenus Samson, Yilmaz, Houbraken, Spierenb., Seifert, Peterson, Varga \& Frisvad (21 and 28), A. japonicas Saito (24), Penicillium oxalicum Currie \& Thom (25), P. chrysogenum Thom (26) and Curvularia lunata (Wakker) Boedijn (49) (Table II).

Among the species tested for enzymatic activity, $A$. sydowii presented better results for production of amylase $(6 \mathrm{~mm})$, lipase $(14 \mathrm{~mm})$ and protease $(5 \mathrm{~mm})$. Two other species produced the three enzymes (A. parasiticus Speare and $P$. fellutanum Biourge), but with less activity. Only three isolates belonging to three species were negative for the three enzymes simultaneously, namely: P. variotii Bainier (04), A. parasiticus Speare (20) and C. lunata (Wakker) Boedijn (49).

Not all isolates of a fungal species necessarily have the same enzyme the same intensity. Therefore our study that although the isolates 14, 27 and 67 belong to the same species Aspergillus parasiticus Speare, the same enzymatic reaction was not observed among them. For, the isolate 27 only produced lipase and the isolates 14 and 67 produced all three enzymes, results the isolates of Talaromyces purpureogenus Samson, Yilmaz, Houbraken,

Spierenburg, Seifert, Peterson, Varga \& Frisvad. The fungi species that presented the best amiolitic activities were Penicillium fellutanum Biourge $(7 \mathrm{~mm})$ and $P$. Oxalicum Currie \& Thom (7 $\mathrm{mm}$ ) and lipase activity were Aspergillus parasiticus Speare (10 mm) and A. sydowii (Bainier \& Sartory) Thom \& Church $(14 \mathrm{~mm})$. The production of protease, although the one of lower intensity for the 
producing species, had the isolate 18 of $A$. sydowii (Bainier \& Sartory) Thom \& Church as the best producer $(5 \mathrm{~mm})$ (Table III). The intensity of the in solid substrate can be directly influenced the solubility, diffusibility, enzyme, other factors.

The results presented in this study show that amiolytic activity was the most common among the species, corroborating with the finding of Wenzel et al. (2013) evaluated endophytic fungi of soybean and revealed a greater quantitative enzymatic activity for the amylase $(83.3 \% 20)$.

The amylase reaction halos in our study varied between 4 and $7 \mathrm{~mm}$ the results found by Firmino and Furtado (2014) the fungus Ceracystis sp., whereas Tavares et al. (2012) $29 \mathrm{~mm}$ halos evaluating Aspergillus isolated from noni (Morinda citrifolia L.).

A study by Soares et al. (2010) for amylase production, suggest that fungi under stress conditions interfere with enzymatic production. Firmino and Furtado (2014) also evaluated lipase activity with isolates of the fungus Ceracystis sp. did not observe any activity for this enzyme. The authors also tested the protease and halos did not exceed $1 \mathrm{~mm}$.

The averages of enzymatic activities of our study differ from the results presented by Griebeler et al. (2015) who found higher values halos above $7.08 \mathrm{~mm}$ for amylase, lipase and protease. These authors worked with isolated fungi from different sources, such as soil, olive and soybean oil, cheeses, tomato extract, cream of milk, meat, soybean meal and contaminated culture media.

A study evaluated fungi isolated Baru seeds, bark and pulp (Dipteryx alata Vog.) and observed that none of the fungi had proteolytic activity, but all of them were able to present some amiolytic and lipolytic activity (Molina et al. 2012). The evaluation performed by Bezerra et al. (2012) with isolates of a Caatinga plant (Opuntia ficus-Mil) revealed that a strain of $A$. japonicas Saito did not produce proteolytic activity, corroborating with our study. Sunitha et al. (2013) enzymatic production differs among fungi and is related to the habitat where it is found.

Aboul-Nasr et al. (2013) tested 110 fungal isolates from intensive care unit air and hospital operating room in India and found that among the 110 isolates tested, 73\% produced protease, lipase and urease, and this was the only the literature testing the enzymatic and mycotoxin production potential of anemophilous fungi. Among the lipase and protease isolates were Aspergillus sp., Cladosporium sp., Myrothecium sp. and Fusarium $\mathrm{sp}$. According to the authors, these results are important since proteases and lipases play a role during microbial infection and suggest these results are important since the extracellular lipases play an important role during microbial infection, since they digest lipids to obtain nutrients by pathogenic microbes, allowing the growth of microbes where lipids are the only source of carbon and proteolytic degradation of lung tissues has been identified as a key phenomenon in the pathophysiology of Aspergillus fumigatus, several species of Aspergillus secrete protease.

In relation to the tests of antibacterial activity of the fungi isolated from the air of the CAV, three metabolic liquids presented activity against all bacteria tested, represented by the species Paecilomyces variotii Bainier (04), Talaromyces purpureogenus Samson, Yilmaz, Houbraken, Spierenb., Seifert, Peterson, Varga \& Frisvad (28) and Aspergillus parasiticus Speare (67). The metabolic liquid of Curvularia lunata (Wakker) Boedijn (49) no antibacterial activity against the bacteria tested (Table IV).

The metabolic liquid of the species Talaromyces purpureogenus Samson, Yilmaz, Houbraken, Spierenburg, Seifert, Peterson, Varga \& Frisvad (isolate 28) presented the best antibacterial activity against all the bacteria tested, reaching the of $125 \mu \mathrm{L} / \mathrm{mL}$, none of the metabolic liquids tested presented bactericidal action, only bacteriostatic. 
Duarte (2006) reports that no consensus what is acceptable the level of inhibition for antimicrobial activity related to natural products versus standard antibioticssome authors consider only antibioticlike results, although others understand that levels inhibition good potential.

The study by Paraginskia et al. (2014) analyzed all bacterial strains evaluated in our study, but used different concentrations of triazenes compounds for antimicrobial activity and obtained bacteriostatic action in at least one of the six evaluated compounds.

\section{CONCLUSIONS}

It was concluded that the environments analyzed in the UFPE/CAV presented great diversity of fungi species they met the requirements of the ANVISA resolution. It was also verified that not present fungi potentially harmful to human health in the environments. Our study demonstrated that some species of anemophilous filamentous fungi are capable of producing the amylase, lipase and protease enzymes the fungi Aspergillus parasiticus Speare and A. sydowii (Bainier \& Sartory) Thom $\&$ Church better amiolytic potential among the other species and enzymes under the conditions of this experiment. The antimicrobial activity of the species Talaromyces purpureogenus Samson, Yilmaz, Houbraken, Spierenburg, Seifert, Peterson, Varga \& Frisvad was the one that presented the best result however, showed low bactericidal potential.

\section{Should read:}

\section{ABSTRACT}

This study aimed to assess the fungal microbiota from the environment of the Federal University of Pernambuco/Vitória Academic Center (UFPE/ $\mathrm{CAV}$ ) and investigate its biotechnological potential in enzymatic and antimicrobial production. In total, 82 air-conditioned environments were sampled using a passive sedimentation technique. The air I/E ratio and the presence of aflatoxigenic strains were evaluated for National Agency of Sanitary Surveillance (ANVISA). In addition, micelles were assessed to determine the enzymatic activity of lipase, amylase, and protease, and five metabolic liquids were assessed to determine antimicrobial activity. Diversity was observed in all CAV environments, $\mathrm{CFU} / \mathrm{m}^{3}$ ranged from 14 to 290 and the I/E ratio ranged from 0.1 to 1.5 . The prevalence of the fungal genera were: Aspergillus (50\%), Penicillium (21\%), Talaromyces (14\%), and Curvularia and Paecilomyces (7\% each). Aspergillus sydowii presented efficient enzymatic activity and the Talaromyces purpurogenus metabolites presented effective antibacterial activity (only bacteriostatic action) against all the tested bacteria. Thereby, we conclude that all environments present fungal species biodiversity; however, no toxigenic or pathogenic fungi were found, according to the ANVISA legislation for air-conditioned environments, and airborne filamentous fungi present potential for enzymatic and antimicrobial activity.

Key words: Air quality, bacteria, enzymes, filamentous fungi, air-conditioned environments.

\section{INTRODUCTION}

Fungi are generally nonpathogenic and can act as opportunistic pathogens. They are widely distributed in natural habitats such as air, water, soil, animals, and food and can effectively colonize various substrates, their geographic distribution is extensive, and they are able to grow under distinct environmental conditions (Oliveira and BorgesPaluch 2015).

Fungal contamination is considered important due to the production of mycotoxin. Certain section of the filamentous fungi, under adequate conditions of oxygen, temperature, and humidity, produce secondary metabolites which can result in 
a vast variety of toxic effects (mycotoxins) for both humans and animals, as is the case of the fungi of the genus Aspergillus and Penicillium. Among the toxigenic species of Aspergillus, Aspergillus flavus and Aspergillus parasiticus are widely known to produce aflatoxins (Peluque 2014).

Thus, monitoring to assess air quality in artificially air-conditioned environments with the objective of determining the presence of microorganisms is crucial. This is stipulated by Resolution RE No. 9 of January 16, 2003, of the National Agency of Sanitary Surveillance (ANVISA), which defines the technical reference standards for cleaning and maintenance of airconditioned systems and for the monitoring of the quality of internal air to assure the health and safety of individuals who attend public and collective places with air-conditioned environments. The maximum recommended acceptable level of microbial contamination of $\leq 750 \mathrm{CFU} / \mathrm{m}^{3}$ and $\leq 1.5$ for the relation between internal and external air $(\mathrm{I} / \mathrm{E})$, ensures unacceptability of the presence of pathogenic and toxigenic fungi (Brazil 2003).

Biotechnically, microbial enzymes are preferred by industries due to their reduced production time, increased scale and purification, specificity and stabilization, as well as their easy genetic manipulation (Nagarajan 2012) and high biochemical diversity (Silva et al. 2015). However, the use of the enzyme by industries is particularly related to the minimization of production cost (Reinehr et al. 2014), waste and electric consumption (Silva et al. 2015). Moreover, the recent status reveals that enzyme trade is profitable due to the requirement of high quality products (Silva et al. 2015).

The dispersion and appearance of microbes which are resistant to commercially available antimicrobial has been described in literature, for years, further encouraging the search for sources of effective antimicrobial agents (Santos et al. 2014). To that effect, several researches with the purpose of intervening, preventing, or intensifying the conventional therapeutic action in bacterial resistance, are being developed (Catão et al. 2014).

Studies testing the antimicrobial properties using mycelia and liquid metabolites of anemophilous filamentous fungi have not been found in literature; therefore, this may be the first study to report such activity. As aforementioned, the present study aimed to evaluate the microbiological quality of air, the presence of aflatoxigenic fungi in the climatic environments of the Federal University of Pernambuco/Vitória Academic Center, and the enzymatic production and antimicrobial activity potential of these fungi.

\section{MATERIALS AND METHODS}

\section{SAMPLING AND COLLECTION OF AIR}

The study was conducted at the Federal University of Pernambuco/Vitória Academic Center (UFPE/ CAV) and comprised 82 artificially air-conditioned environment samples: 3 from the board rooms, 9 from the library, 1 from the auditorium, 15 from classrooms, 34 from laboratories, 13 from administrative rooms, 1 from the Internal Accident Prevention Commission (CIPA) room, 5 from the student assistance centers, and 1 from the teaching staff room, in addition to samples from an external area located in the courtyard of the main entrance of the CAV, for fungi quantification. Non airconditioned environments were excluded from the study.

The samples were collected from the central area of the environments through the passive sedimentation technique (Lacaz et al. 1998) on solid culture medium using Petri dishes containing the culture media of malt extract agar (MEA) plus chloramphenicol and Aspergillus flavus and parasiticus agar (AFPA) for total fungi and aflatoxigenic fungi cultures, respectively. The plates were placed $1 \mathrm{~m}$ above the ground and were opened for $15 \mathrm{~min}$ to insert the bioaerosols containing 
microorganisms present in the atmospheric air. The plates were then incubated at room temperature (28 $\pm 2^{\circ} \mathrm{C}$ ) for up to 4 days.

\section{MICROBIOLOGICAL ANALYSIS OF AIR}

After fungal growth, the colonies present in the respective culture media were quantified and the relation between internal and external air (I/E) was calculated to determine the internal air quality. ANVISA stipulates the recommended maximum acceptable microbiological contamination value to be $\leq 750 \mathrm{CFU} / \mathrm{m}^{3}$ and $\leq 1.5$ for the relationship between internal and external air (Brazil 2003).

Sedimentation sampling does not directly determine the number of microorganisms present in a given volume of air, however, it is possible to transform the results of this method (number of CFU/unit area) into CFU/volume unit number (Morais et al. 2010). Thus, air sampling by sedimentation was calculated using the following equation, described by Friberg et al. (1999),

No. of CFU $/ \mathrm{m}^{3}=\frac{\text { No of CFU on plate }}{\text { Petri dish area }\left(\mathrm{m}^{2}\right)} \times \frac{1}{23}$

where the area of the petri dish was $90 \times 15 \mathrm{~mm}$ (our study, $0.006 \mathrm{~m}^{2}$ ). SAR is the ratio between the microbial count in the air and (in the microbial count) on the surface of the culture medium. For environments with spontaneous sedimentation and without apparatus that forces the sedimentation of air, this ratio is 1:23 (Morais et al. 2010).

\section{IDENTIFICATION OF AFLATOXIGENIC FUNGI}

The possibility of the presence of aflatoxigenic strains, revealed by the bright orange-yellow reverse pigmentation of the AFPA culture medium, was assessed. ANVISA deems unacceptable the presence of pathogenic and toxigenic fungi in artificially climatized environments (Brazil 2003).
ISOLATION, IDENTIFICATION, AND PRESERVATION OF FUNGI

Following the fungal growth in the MEAsolid culture medium, the fungal colonies were purified in the same culture medium. After identifying the fungal species, the macroscopic (coloration, appearance, and diameter of the colonies) and microscopic (somatic and reproductive microstructures) characteristics (Samson and Frisvad 2004) were observed through culture under coveralls (Riddell 1950) and then preserved according to the Castelani method (distilled water and immersion of pure cultures in mineral oil). Subsequently, the samples were collected in test tubes containing MEA solid culture medium in order to place each identified species in the Collection of Cultures Micoteca URM of the Federal University of Pernambuco.

\section{DETERMINATION OF ENZYMATIC ACTIVITY}

To determine the enzymatic activity of the fungi isolated from the air, 14 species were identified [Paecilomyces variotii Bainier (species 04), Penicillium fellutanum Biourge (species 06), Aspergillus flavus Link (species 09), Aspergillus parasiticus Speare (species 14, 20, 27 and 67), Aspergillus sydowii (Bainier \& Sartory) Thom \& Churc (species18), Talaromyces purpurogenus Samson, N. Yilmaz, Houbraken, Spierenb., Seifert, Peterson, Varga \& Frisvad (species 21 and 28), Aspergillus japonicus Satio (species 24), Penicillium oxalicum Currie \& Thom (species 25), Penicillium chrysogenum Thom (species 26), and Curvularia lunata (Wakker) Boedijn (species 49)] for lipase, amylase, and protease production, following the methodology of Menezes and Hanlin (2004). Mycelial disks were created from fungal colonies and were peeled into the central area of the Petri dish containing particular culture media specific for each enzyme; these were further incubated for 5 days at room temperature. The 
tests were performed in triplicate for each culture medium.

The lipase reaction was studied by visualizing the presence of calcium salt crystals of lauric acid and/or the formation of a clear area around the fungal colony disk. To verify the production of amylase, $0.1 \mathrm{~N}$ iodine solution was used, enabling the identification of the enzymatic reaction by means of a translucent halo around the colony. For protease, due to the chemical reaction, it was possible to visualize the formation of a translucent halo around the colony. Following the development of the enzymatic reactions, a halo of enzymatic activity was measured to determine the production potential of the colonies, which is proportional to the diameter of the halo.

\section{DETERMINATION OF ANTIBACTERIAL ACTIVITY}

From the species identified, 5 metabolic liquids from the species Paecilomyces variotii Bainier (04), Aspergillus japonicus Satio (24), Talaromyces purpurogenus Samson, N. Yilmaz, Houbraken, Spierenb., Seifert, Peterson, Varga \& Frisvad (28), Curvularia lunata (Wakker) Boedijn (49), and Aspergillus parasiticus Speare (67) were randomly selected for the performance of antimicrobial activity and for the determination of the minimum inhibitory concentration (MIC) and minimum bacteriostatic concentration (MBC). Purified fungal mycelial disks were cultured in $10 \mathrm{~mL}$ of liquid culture medium Sabouraud broth and incubated at room temperature for 20 days. Following this procedure, the liquid metabolite was separated from the mycelium by filtration on sterile filter paper. The metabolic fluid was stored at $4^{\circ} \mathrm{C}$ to perform the antibacterial activity tests and the mycelium was frozen for subsequent extraction of metabolites.

The following strains of bacteria were used for bacterial suspensions; Gram-negative bacteria: Escherichia coli (ATCC 25922), Shigella flexneri (ATCC 12022), Salmonella typhimurium (ATCC 14028), Serratia marcescens, Klebsiella pneumoniae, and Pseudomonas aeruginosa, and Gram-positive bacteria: Staphylococcus aureus (ATCC 29213) and oxacillin resistant S. aureus (ORSA). The bacterial suspensions were prepared in $0.85 \%$ saline and a concentration of $1.5 \times 10^{-5}$ $\mathrm{CFU} / \mathrm{mL}$ was obtained from the dilution of the corresponding suspension to the 0.5 tube of the McFarland scale. Five metabolic liquids produced by filamentous fungi from atmospheric air were tested. All experiments were performed in triplicate.

The antibacterial activity test was performed as per the broth dilution method of the ANVISA M7-A6 technical standard. Serial dilutions of metabolic liquids were performed. Positive control of the test was performed, using $0.05 \mathrm{mg} / \mathrm{mL}$ of chloramphenicol antibiotic and the negative control of the test was performed in the absence of antibiotic. and then they were both tested for sterility. Following the distribution of the bacterial suspensions, the plates were incubated at $37^{\circ} \mathrm{C}$ for $24 \mathrm{~h}$. A solution of $20 \mu \mathrm{L}$ 2,3,5-triphenyltetrazolium chloride (TTC) $(2 \% \mathrm{v} / \mathrm{v})$, diluted in water, was added to all wells after $2 \mathrm{~h}$ of incubation at room temperature, to check for bacterial growth. The wells stained in red indicated bacterial growth (Rahman et al. 2004).

The red coloration is a result of the reaction of triphenyl tetrazolium chloride (TTC) with hydrogen ions constituted due to cellular respiration, generated by an insoluble reddish solution called formazan, indicating viable bacterial cells in the medium (Rahman et al. 2004).

The Minimum Inhibitory Concentration (MIC) reading was performed by means of visual observation of the lowest concentration of metabolic liquids that acted towards inhibiting bacterial growth. Next, the Minimum Bactericidal Concentration (MBC) test was performed, where the wells with visual inhibition of bacterial growth and the wells before them were sterilized with a 
sterile $1 \mu \mathrm{L}$ loop. This procedure was repeated for Petri dishes containing Mueller-Hinton Agar, and the plates were incubated at $37^{\circ} \mathrm{C}$ for $24 \mathrm{~h}$. Following this period, the plates were observed for bacterial growth, indicating either bactericidal or bacteriostatic action of the fungal metabolite, in which the wells not presenting antimicrobial activity were stained red.

The liquid metabolites used in the study were tested in their crude state after filtration. Therefore, the antimicrobial activity took into consideration the inhibitory concentrations specified for the method in $\mu \mathrm{L} / \mathrm{mL}$ following serial dilutions: 500.00; 250.00; $125.00 ; 62.50 ; 31.25 ; 15.63 ; 7.81$; $3.91 ; 1.95$; and $0.97 \mu \mathrm{L} / \mathrm{mL}$.

\section{RESULTS AND DISCUSSION}

Fungal growth was observed in all environments, with the lowest amount of $\mathrm{CFU} / \mathrm{m}^{3}$ (14) being found in the classroom, and the highest amount and diversity of fungal colonies in the living pharmacy space (one of the labs), the CIPA room, and the teaching staff room, all showing $290 \mathrm{CFU} / \mathrm{m}^{3}$ of air as shown in Table I. Nonetheless, all the assessed environments of the CAV were within the limits permitted by ANVISA for the microbiological quality of the air $\left(\leq 750 \mathrm{CFU} / \mathrm{m}^{3}\right)$. Diversified fungal colonies from distinct environments were observed. Figures 1 and 2 report the colonies before and after purification of the fungal isolates, respectively.

The contamination observed in the evaluated environments may possibly be associated to the accesses to the building, the flow of ventilation and to people who pass through the environments, due to the fact that the external atmosphere is influenced by the climate, whereas the internal atmosphere is influenced by building maintenance. Environments with both internal and external atmosphere are influenced by human activities, humidity, and fairly influenced by temperature, since many indoor fungi grow in a wide range of temperatures (Araújo and Cabral 2010).

The ratio of fungi quantification of $\mathrm{I} / \mathrm{E}$ (internal/external) of the environments surveyed in the CAV (Table I) met the current requirements of the ANVISA legislation for air quality in airconditioned environments $(\leq 1.5)$, the ratio varying from 0.1 to 1.5 , the minimum and maximum, respectively, since the external air quantification was $188 \mathrm{CFU} / \mathrm{m}^{3}$.

The environments that presented an I/E relationship in the maximum acceptable limit were: library entrance hall, living pharmacy space, CIPA room, and microscopy laboratory 1 , and teaching staff room. The explanation for this is that the entrance hall of the library is the area most frequented by visitors, indicationg that human activity has a direct influence on the quantity of bioaerosol; the live pharmacy laboratory handles plant and soil samples, from which the fungi can be released into the air; the CIPA room is an environment used for meetings, thus is more populated; and the teacher's room is frequented by students, and due to the fact of being a small room, suffers the influence of human activity. In these aforementioned environments, the values of the air fungi quantification in $\mathrm{CFU} / \mathrm{m}^{3}$ were less than those permitted by ANVISA (750), but the I/E ratio was within the set limit.

None of the environment presented aflatoxigenic fungi (Fig. 3) thus were in compliance with the aforementioned legislation that establishes the absence of pathogenic and toxigenic fungi in indoor air.

In contrast to our study, Aboul-Nasr et al. (2013) found toxigenic fungi, isolated from the intensive care unit of a hospital in India. Of the 110 fungal isolates obtained from said hospital environment, 79 isolates were tested by thin layer chromatography (TLC), and at least one mycotoxin was produced from these 79 isolates. Several mycotoxins are detected by TLC, the main 
aflatoxins being zearalenone, gliotoxin, fumigiline, etc. Mycotoxin production is known to be a virulence factor.

The frequency of the fungal genera, found in the analyzed CAV environments, whose isolates could be identified were: Aspergillus (50\%), Penicillium (21\%), Talaromyces (14\%), Curvularia, and Paecilomyces (7\% each), as shown in Figure 4.

Anemophilous fungal infections are well known in medical literature, and the inhaled airborne spores have been implicated to be responsible for various allergic reactions (Furtado and Ferraroni 1982). In addition to allergy cases, many opportunistic fungi such as those shown in Figure 4, are responsible for several diseases namely otitis, mycotoxicosis, urinary infections, onychomycosis, eye infections, and fungemia. The toxigenic and pathogenic nature of these fungi is of major concern, since they are dispersed abundantly in the environment (Grumach 2001). Therefore, the monitoring of the environment to detect potential pathogenic fungi ny means of a rapid, sensitive, and reliable approach to detect microorganisms is necessary to prevent epidemics and protect public health (Zhoug et al. 2000).

Biologically, fungi are considered a promising source for new biomolecules with diverse biological activities for enzyme production and antimicrobial activity, due to their chemical and structural diversity (Silva et al. 2015).

Most studies on air quality were performed in hospital settings. Azimi et al. (2013) analyzed the microbial quality of hospital air and found that $70 \%$ of the 120 samples contained fungi of Penicillium sp., 14\% contained Aspergillus sp., 12\% contained Cladosporium sp., and 25\% Alternaria sp., indicating a risk factor for patients and professionals in these environments. This result is contradictory to that of our study, since in addition to the analyzed environment being different, the most frequently seen fungi in our study was Aspergillus sp.
Few studies have been carried out in university environments, of which most were performed in university libraries or schools, due to the influence of air quality on children's health. University libraries are often studied due to being air-conditioned and due to the fact that they are well visited by many students. The results obtained for the CAV library are similar to those obtained by Nascimento (2011) who upon analyzing the internal air quality of the public library of the city of São Carlos/SP, did not find irregularities that would confront ANVISA's legislation.

The 14 CAV classrooms presented values below $750 \mathrm{CFU} / \mathrm{m}^{3}$. However, the results of this study differ from those presented by Morais (2010), who, upon assessing the microbiological quality of air in classrooms of a higher education institution, reported that $51 \%$ of the classrooms presented contamination superior to that stipulated by ANVISA.

Stryjakowska-Sekulska et al. (2007) studied nine environments at the University of Poznan in Poland. Samples were collected from two classrooms, a chemistry laboratory, a library, a canteen, restrooms, and the board room. All environments were evaluated in the morning and in the afternoon, for 2 years. The authors reported higher frequency of bacteria and fungi in the afternoon, possibly due to the increased population attending these environments throughout the day. They observed the following fungal genera in order of prevalence in the environments: Cladosporium sp., Penicillium sp., Aspergillus sp., Alternaria sp., Mucor sp., Rhizopus sp., and Epicocum sp. This result correlates to our study, since Aspergillus and Penicillium were also the most frequent genera found in the CAV environment; according to Agarwal and Chakrabarti (2010), these genera, as well as Curvularia, are the first colonizers of surfaces and interiors.

Pantoja et al. (2007) studied five sites (classroom, central library, main warehouse, food 
court, and an area of preservation) of the Campus of the State University of Ceará, Campus Itaperi. Among the 18 genera isolated from the evaluated environments, the most commonly found were Aspergillus sp. (78\%), Penicillium sp. (30\%), and Fusarium sp. (22\%). The classroom and central library were found to be the most contaminated indicating the importance of human activity as the main factor influencing contamination of mycobiota in these environments.

It is worth mentioning that Pantoja et al. (2007) found many fungal genera due to the fact that the collection method, despite being passive sedimentation, extrapolated the air collection time generally recommended in the world literature, which is of $15 \mathrm{~min}$, and the samples were collected for $12 \mathrm{~h}$.

The concern in finding the genus Aspergillus and Penicillium in indoor and air-conditioned environments is due to certain species of these genera producing secondary metabolites with a toxic effect on health (Peluque 2014). Exposure to mycotoxins may lead to reactions including hemorrhages and necrosis, and when in abundance, such toxins have affinity for specific organs or tissues such as the liver, kidneys, and the nervous system (IARC 2002).

Kalwasinska et al. (2012) evaluated functional and nonfunctional environments of a university library in Torun, Poland. According to the authors, the internal air was described as being of low risk, as per to the country's legislation, both in the functional (classroom, newspaper reading room, collection conservation room), and in nonfunctional (bathroom, cafeteria) environments. Said results contradict our results in which all sectors of the CAV library analyzed, presented levels below the limit established by ANVISA (Table I).

According to Boff (2011), environments with fungal agglomerates are influenced by environmental factors such as temperature, humidity, airflow, available organic substrates, climatic conditions and seasonal variation, as well as by physical factors including the shape, size, and density of the particles, among other situations that corroborate the increase of conidia in the environment.

Ejdys et al. (2013) studied the fungal composition of air from school classrooms and monitored them for 4 years, classifying the air according to biosafety level. The authors isolated 151 species of fungi, of which 22 were of class 2 and 61 were classified as class 1 of biological risk.

Hayleeyesus and Manaye (2014) studied university libraries from Ethiopia and observed that the air rated as highly contaminated, as per the country's legislation, with concentrations of fungi ranging from 367 to $2595 \mathrm{CFU} / \mathrm{m}^{3}$. Aspergillus sp., Penicillium sp., Alternaria sp., Cladosporium sp., and Fusarium sp. were the most frequently found in these libraries. These results correlated with those found in our study for the library and other environments of the CAV.

Many fungal species, including those present in the air, can be responsible for the production of diverse metabolites with the most varied industrial and biological applications, including enzymatic and antimicrobial activities (Viriato 2014).

Yet, the sources for fungal extraction, for the study of biological activities are soil, water, plants, and more recently marine environments, exploring the secondary metabolism with the purpose of performing tests using liquids and metabolic extracts or metabolites isolated by chromatography. The fungi in atmospheric air that contain a range of pollutants are still an unexplored area with regards to the isolation of fungi that can possibly present some sort of biological activity.

Of the fungi found in air, initially 67 specimens were isolated and then subsequently 14 isolates were tested following morphological identification to determine the enzymatic activity for the production of amylase, lipase, and protease. The species of filamentous fungi identified in the air of the CAV 
were Paecilomyces variotii Bainier (04), Penicillium fellutanum Biourge (06), Aspergillus flavus Link (09), Aspergillus parasiticus Speare (14, 20, 27, and 67), Aspergillus sydowii (Bainier \& Sartory) Thom \& Church (18), Talaromyces purpurogenus Samson, N. Yilmaz, Houbraken, Spierenb., Seifert, Peterson, Varga \& Frisvad (21 and 28), Aspergillus japonicus Satio (24), Penicillium oxalicum Currie \& Thom (25), Penicillium chrysogenum Thom (26), and Curvularia lunata (Wakker) Boedijn (49) (Table II).

Among the species tested for enzymatic activity, Aspergillus sydowii (Bainier \& Sartory) Thom \& Church presented the best results for the production of amylase $(6 \mathrm{~mm})$, lipase $(14 \mathrm{~mm})$, and protease $(5 \mathrm{~mm})$. Two other species produced the three enzymes (Aspergillus parasiticus Speare and Penicillium fellutanum Biourge), yet with lower activity. Only three isolates belonging to three species were negative for the three enzymes simultaneously, namely: Paecilomyces variotii Bainier (04), Aspergillus parasiticus Speare (20), and Curvularia lunata (Wakker) Boedijn (49).

Not all isolates of a fungal species necessarily have the same enzyme with the same intensity. Therefore, our study observed that despite isolates 14, 27, and 67 belonging to the same species $A$. parasiticus Speare, the same enzymatic reaction was not observed among them. Isolate 27 only produced lipase and isolates 14 and 67 produced all three enzymes, with similar results being observed for isolates of Talaromyces purpurogenus Samson, N. Yilmaz, Houbraken, Spierenb., Seifert, Peterson, Varga \& Frisvad.

The fungi species that presented the best amiolitic activities were Penicillium fellutanum Biourge $(7 \mathrm{~mm})$ and Penicillium oxalicum Currie \& Thom $(7 \mathrm{~mm})$, and those presenting the best lipase activity were Aspergillus parasiticus Speare (10 $\mathrm{mm}$ ) and Aspergillus sydowii (Bainier \& Sartory) Thom \& Church (14 mm). Whereas, the production of protease, despite being the one with lowest intensity for the producing species, indicated isolate 18 of $A$. sydowii as the best producer (5 $\mathrm{mm}$ ), as shown in Table III. The intensity of the production of enzyme in solid substrate can be directly influenced by the solubility, diffusibility, and size of enzyme, among other factors.

The results presented in this study show that amiolytic activity was the most common among the species, corroborating with the finding of Wenzel et al. (2013), who assessed endophytic fungi of soybean and revealed a greater quantitative enzymatic activity for amylase $(83.3 \%, 20)$.

The amylase reaction halos in our study varied between 4 and $7 \mathrm{~mm}$, which were greater than the results found by Firmino and Furtado (2014) who obtained a halo of up to $1 \mathrm{~mm}$ upon studying the fungus Ceratocystis spp. whereas in the study conducted by Tavares et al. (2012), $29 \mathrm{~mm}$ halos were observed while assessing Aspergillus isolated from noni (Morinda citrifolia L.).

A study by Soares et al. (2010) for amylase production, suggests that fungi under stressful conditions suffer influences that interfere with the enzymatic production. Firmino and Furtado (2014) also assessed lipase activity with isolates of the fungus Ceratocystis spp. and did not observe any activity for this enzyme. The authors also tested the protease and observed that the halos did not exceed $1 \mathrm{~mm}$.

The averages of enzymatic activities of our study differ from those presented by Griebeler et al. (2015), who found higher values for amylase halos (over $7.08 \mathrm{~mm}$ ) and for protease (over $10.62 \mathrm{~mm}$ ). These authors worked with fungi isolated from different sources, such as soil, olive and soybean oil, cheeses, tomato extract, dairy cream, meat, soybean meal, and contaminated culture media.

Astudy assessed fungi isolated from Baru seeds, bark, and pulp (Dipteryx alata Vog.) and observed that none of the fungi indicated proteolytic activity, yet all of them were able to present some amiolytic and lipolytic activity (Molina et al. 2012). The 
assessment performed by Bezerra et al. (2012) with isolates of a Caatinga plant (Opuntia ficus-Mil) revealed that a strain of Aspergillus japonicus did not produce proteolytic activity, corroborating with our study. A study by Sunitha et al. (2013) revealed that enzymatic production differs among fungi and is related to the habitat in which it is found.

Aboul-Nasr et al. (2013) tested 110 fungal isolates from the air of intensive care unit and hospital operating rooms in India and found that among the 110 isolates tested, $73 \%$ produced protease, $92 \%$ produced lipase and $78 \%$ produced urease, being this the only study in the literature testing enzymatic and mycotoxin production potential of anemophilous fungi. Among the isolates that produced lipase and protease were Aspergillus sp., Cladosporium sp., Myrothecium sp., and Fusarium sp. According to the authors, these results are important since proteases and lipases play an important role in microbial infection. Furthermore they suggest that the pathogens have the capacity of digesting lipids of the host membrane and that protease degrades lung tissues which is indicated as being one of the events involved in the pathophysiology of Aspergillus fumigatus infection, which together with Aspergillus flavus, a producer of aflatoxin, is known to secrete protease.

With regards to the tests of the antibacterial activity of the fungi isolated from the air of the CAV, three metabolic liquids presented activity against all bacteria tested, represented by the species Paecilomyces variotii Bainier (04), Talaromyces purpurogenus Samson, N. Yilmaz, Houbraken, Spierenb., Seifert, Peterson, Varga \& Frisvad (28) and Aspergillus parasiticus Speare (67). The metabolic liquid of Curvularia lunata (Wakker) Boedijn (49) did not present ant antibacterial activity against the bacteria tested (Table IV).

The metabolic liquid of the species Talaromyces purpurogenus Samson, N. Yilmaz, Houbraken, Spierenb., Seifert, Peterson, Varga \& Frisvad (isolate 28) was the one which presented the best antibacterial activity against all the bacteria tested, reaching the MIC of $125 \mu \mathrm{L} / \mathrm{mL}$. Yet, none of the metabolic liquids tested presented bactericidal action, only bacteriostatic action was observed.

Duarte (2006) reports that there is no consensus as to what is acceptable regarding the level of inhibition for antimicrobial activity with regards to the use of natural products versus standard antibiotics; some authors consider only antibioticlike results, whereas others understand that levels of high inhibition, reveal good potential.

The study by Paraginskia et al. (2014) analyzed all the bacterial strains assessed in our study, but used different concentrations of triazenes compounds for antimicrobial activity and obtained bacteriostatic action in at least one of the six compounds assessed.

\section{CONCLUSIONS}

It was concluded that the environments analyzed in the UFPE/CAV, presented great diversity of fungi species, yet they met the demands specified by ANVISA's resolution. It was also verified that these environments did not present fungi potentially harmful to human health in the airconditioned environments. Our study demonstrated that some species of anemophilous filamentous fungi are capable of producing the amylase, lipase, and protease enzymes. However, the fungi Aspergillus parasiticus Speare and Aspergillus sydowii (Bainier \& Sartory) Thom \& Church stand out due to possessing the best amiolytic potential among all other species and enzymes tested under the same conditions of this experiment. The antimicrobial activity of the species Talaromyces purpurogenus Samson, N. Yilmaz, Houbraken, Spierenb., Seifert, Peterson, Varga \& Frisvad was the one that presented the best result, yet, it showed low bactericidal potential. 
PAGE 2336, TABLE II:

Reads:

variotti

\section{Should read:}

variotii

PAGE 2337, TABLE III:

Reads:

variotti
Should read:

variotii

PAGE 2338, TABLE IV:

Reads:

variotti

Should read:

variotii 